\title{
SYSTEMS, SCIENCE AND SOFTWARE
} SAN FRANCISCO DIVISION

\author{
DOE/DP/40064-1
}

DEVELOPMENT OF SPARK CATHODE

ELECTRON GUNS FOR THE $\mathrm{CO}_{2}$ LASER FUSION PROGRAM

FINAL REPORT

JULY 1978 - DECEMBER 1979

G. K. LODA

R. A. LINDSTRAND

JANUARY 1980

\section{PREPARED FOR}

DEPARTMENT OF ENERGY

NEVADA OPERATIONS OFFICE

UNDER CONTRACT DE-AC08-78DP40064

P.O. BOX 4803, HAYWARD, CALIFORNIA 94540, TELEPHONE (415) 785-8040 


\section{DISCLAIMER}

This report was prepared as an account of work sponsored by an agency of the United States Government. Neither the United States Government nor any agency Thereof, nor any of their employees, makes any warranty, express or implied, or assumes any legal liability or responsibility for the accuracy, completeness, or usefulness of any information, apparatus, product, or process disclosed, or represents that its use would not infringe privately owned rights. Reference herein to any specific commercial product, process, or service by trade name, trademark, manufacturer, or otherwise does not necessarily constitute or imply its endorsement, recommendation, or favoring by the United States Government or any agency thereof. The views and opinions of authors expressed herein do not necessarily state or reflect those of the United States Government or any agency thereof. 


\section{DISCLAIMER}

Portions of this document may be illegible in electronic image products. Images are produced from the best available original document. 


\section{NOTICE}

This report was prepared to document work sponsored by the United States Government. Neither the United States nor its agent, the United States Department of Energy, nor any Federal employees, nor any of their contractors, subcontractors or their employees makes any warranty, expressed or implied, or assumes any legal liability or responsibility for the accuracy, completeness, or usefulness of any information, apparatus, product or process disclosed, or represents that its use would not infringe privately owned rights.

Reference to a company or product name does not imply approval or recommendation of the product by Systems, Science and Software or the U.S. Department of energy to the exclusion of others that may be available.

Printed in the United States of America

Available from:

National Technical Information Service

U.S. Department of Commerce

5285 Port Royal Road

Springfield, Virginia 22161

Price:

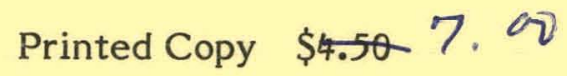




\section{DEVELOPMENT OF SPARK CATHODE ELECTRON GUNS FOR THE $\mathrm{CO}_{2}$ LASER FUSION PROGRAM}

FINAL REPORT

JULY 1978 - DECEMBER 1979

G. K. LODA R. A. LINDSTRAND

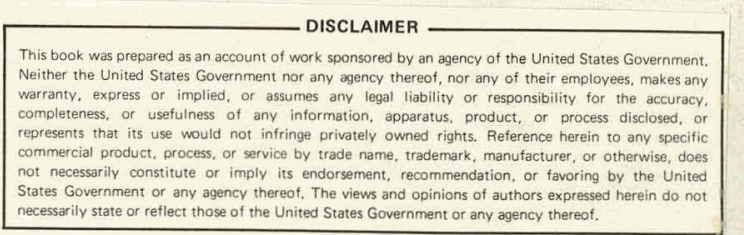

PREPARED FOR

DEPARTMENT OF ENERGY

NEVADA OPERATIONS OFFICE

UNDER CONTRACT DE-AC08-78DP40064 


\begin{abstract}
Spark cathodes are designed and constructed to replace the bladed cold cathode structure in the electron guns of the Los Alamos Scientific Laboratory, Antares, prototype power amplifier and driver amplifier. Design work is described and data from cathode testing is reported. The spark cathode offers precise control of emission site location, design flexibility, and high reliability.
\end{abstract}


TABLE OF CONTENTS

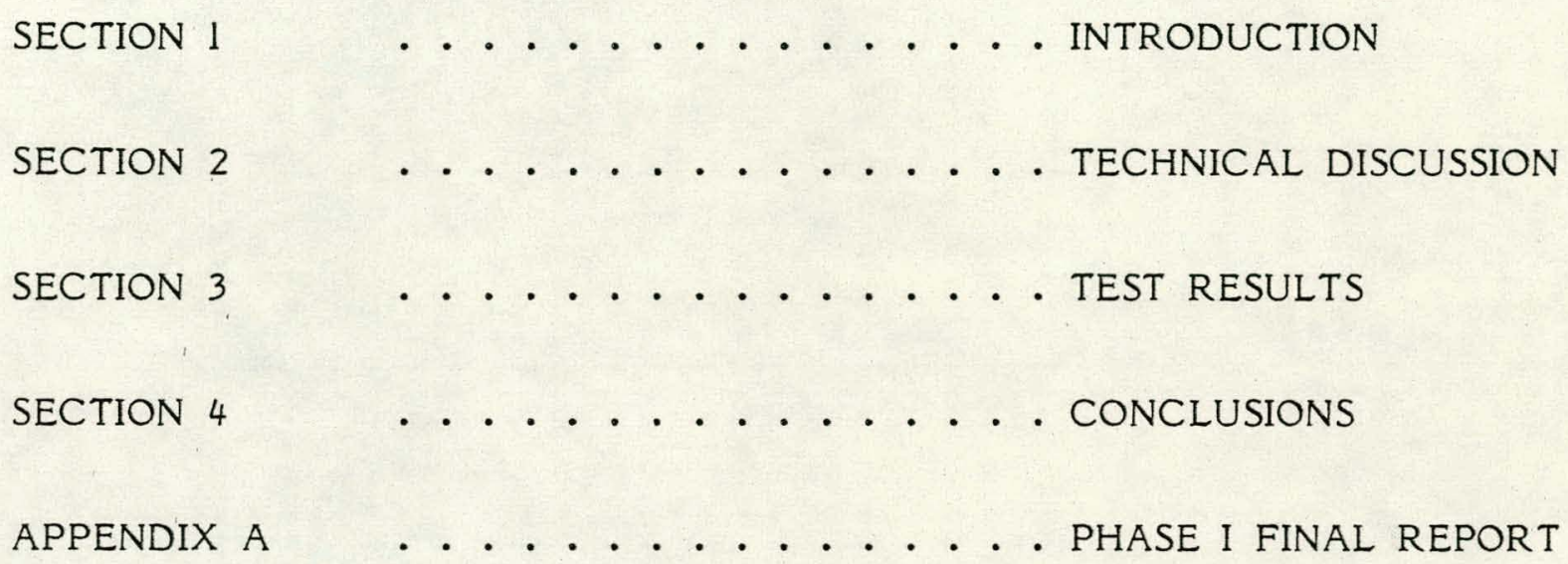




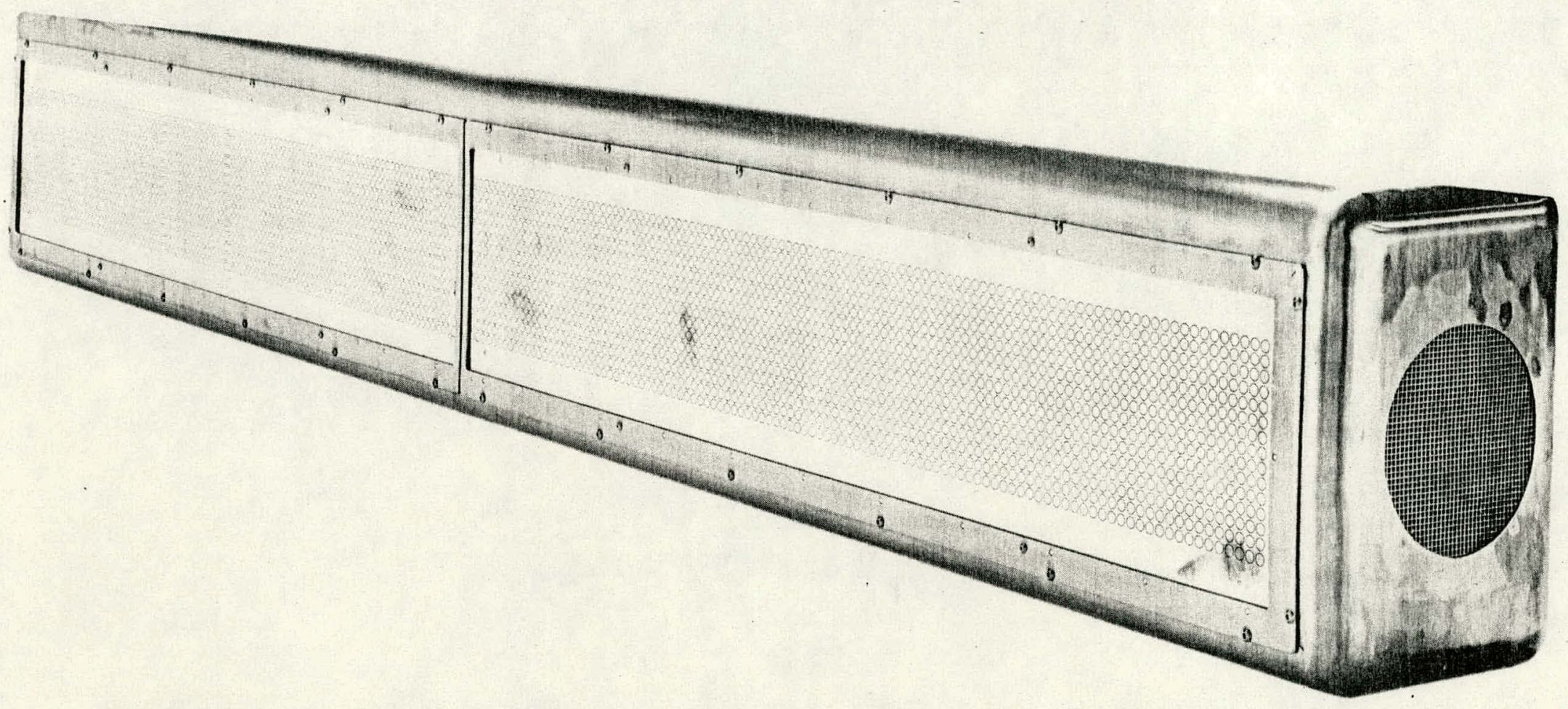

Driver Amplifier Spark cathode Assembly. 


\section{SECTION 1}

\section{INTRODUCTION}

This document is the final report for the two phase program entitled "Development of Spark Cathode Electron Guns for the $\mathrm{CO}_{2}$ Laser Fusion Program" (SSS-P-78-84100-85). The report will review the electron gun requirements for such lasers, describe the technical effort, and discuss the experimental results. The final report for the first phase of the program is included as an appendix.

The current thrust of the $\mathrm{CO}_{2}$ laser fusion project at Los Alamos Scientific Laboratory (LASL) is to build an appropriate laser system to drive a laser fusion reaction achieving scientific breakeven energy output. At the same time, emphasis is placed on the laser system engineering in light of the need to ultimately build an operational laser fusion power plant.

The LASL Antares laser fusion project, now under construction, will utilize numerous, large area, electron guns to control the main laser discharge. Each of the six giant power amplifiers has 48 separate electron beam windows. They are arranged in a 3 meter long, cylindrical geometry. There are 4 windows along each amplifying path, resulting in 12 amplified laser beams per amplifier. In addition, the three driver laser amplifiers feeding the power amplifiers will produce 2 electron beams each. The result is the routine operation of nearly 300 electron beam cathodes.

The reliability and maintainability of such complex systems dictate long component lifetimes for practical power plant operation. Antures system projected lifetime is $10^{4}$ shots and successful power plant maintenance periods will approach $10^{7}$ shots. Cold cathode guns using blade emitters typically exhibit a gradually deteriorating, $10^{3}$, shot lifetime. However, spark cathode type emitters, initially developed by Systems, Science and Software (S-Cubed) for the Defense Advanced Research Projects Agency under contract number DASG-60-77-C-0124, provide the potential to achieve the desired lifetime goals. 
In addition to this, the incorporation of such spark cathodes permits more flexibility in electron gun power supply design and may provide for easier cathode assembly.

To demonstrate the capabilities of spark cathode emitters as a replacement for blade cathode emitters, S-Cubed designed and fabricated cathodes for test and evaluation on both the Antares power amplifier prototype and the initial driver amplifier. Both cathode assemblies were installed and subjected to limited testing. Overall Antares project schedules required that more extensive evaluation be conducted at a later date. Significant experimental data were acquired to facilitate design of large area cathodes for future electron guns. 


\section{SECTION 2}

\section{TECHNICAL DISCUSSION}

\section{Power Amplifier Prototype}

The LASL Antares power amplifier prototype was originally designed to confirm the scale-up physics of large volume, $\mathrm{CO}_{2}$, laser amplifiers. Following completion of this investigation, the prototype was converted to an engineering test facility for evaluating full size amplifier components. A major effort involved further study of large, cylindrical, grid-controlled, cold cathode electron gun performance. This was an extension of the previous evaluation performed by S-Cubed under LASL Purchase Order Number L66-21680-1. The recent work by LASL addressed such topics as suppression of grid emission, reduced voltage operation, and effects of emitter location on transmitted electron beam current density. It was during this phase of testing that the spark cathode supplied by S-Cubed was installed.

The spark cathode is 12-sided and approximately 1.3 meters in length. Detailed description of the design and construction of the spark cathode is contained in Appendix A - Phase I Final Report. At the time of writing of the Phase I report, the cathode structure had been delivered following initial computer simulation, life testing and full scale, low voltage modeling at SCubed. Cathode installation and test at LASL in the Antares prototype occurred later and will be described in this report.

The cathode consisted of 12 spark boards, each roughly $15 \mathrm{~cm}$ wide $x$ $1.3 \mathrm{~m}$ in length, providing a linear emission site density of 20 sites per meter. Each emission site resulted from the individual surface flashover of large ( 5 $\mathrm{cm} \times 7 \mathrm{~cm}$ ), capacitively isolated, or "floating", electrodes.

One additional benefit of spark cathode design was determined during the installation of the cathode. The assembly of the 12-sided spark cathode array was found to require significantly less manhours than the equivalent assembly of the blade cathode. 


\section{Driver Amplifier}

The 72 laser beams of the Antares laser system will be generated by beam splitting of the six driver amplifier outputs prior to passage through the power amplifiers. The beam splitting will be accomplished through the use of a 12-sided polyhedron which will break up each of the six, $15 \mathrm{~cm} O D$, annular beams. This method of beam expansion necessitates a high degree of initial laser beam uniformity. The six, highly uniform, amplified laser beams are to be produced by three, S-Cubed designed and constructed, dual beam, driver amplifier modules. One of these is shown in Fig. 2.1. The two discharges of the dual beam module are controlled by a single, two-sided, cold cathode, electron gun. The full system's three electron guns are to be driven from a single pulse forming network ( $p f n$ ).

The driver amplifier electron gun and one discharge chamber are shown in Fig. 2.2. The tank appearing on the top of the electron gun vacuum chamber houses a high voltage peaking switch coupling the pfn output cable to the cathode feed. This gun, like those in the power amplifier, is grid controlled. The two electron beam transmission windows individually measure $17 \mathrm{~cm} \times 200 \mathrm{~cm}$. Typical electron energies are $350 \mathrm{keV}$ with current densities around $50 \mathrm{~mA} / \mathrm{cm}^{2}$.

The design of the driver electron gun permitted easy conversion to spark cathode operation. The blade emitter and focusing electrode of the cathode assembly are completely removed, leaving the grid assembly in place. The spark cathode assembly (Fig. 2.3) is then bolted into position.

The spark boards of the cathode assembly are approximately 1 meter long and $40 \mathrm{~cm}$ high, with two required for each side of the two meter gun. The active area of each board measures $15 \mathrm{~cm} \times 100 \mathrm{~cm}$. The electron emission sites are generated from surface flashover of $\sim 3000$ "floating" electrodes per side, arranged in a 1 site $/ \mathrm{cm}^{2}$ pattern. Fig. 2.4 is a photograph of the cathode assembly showing the spark board design. 


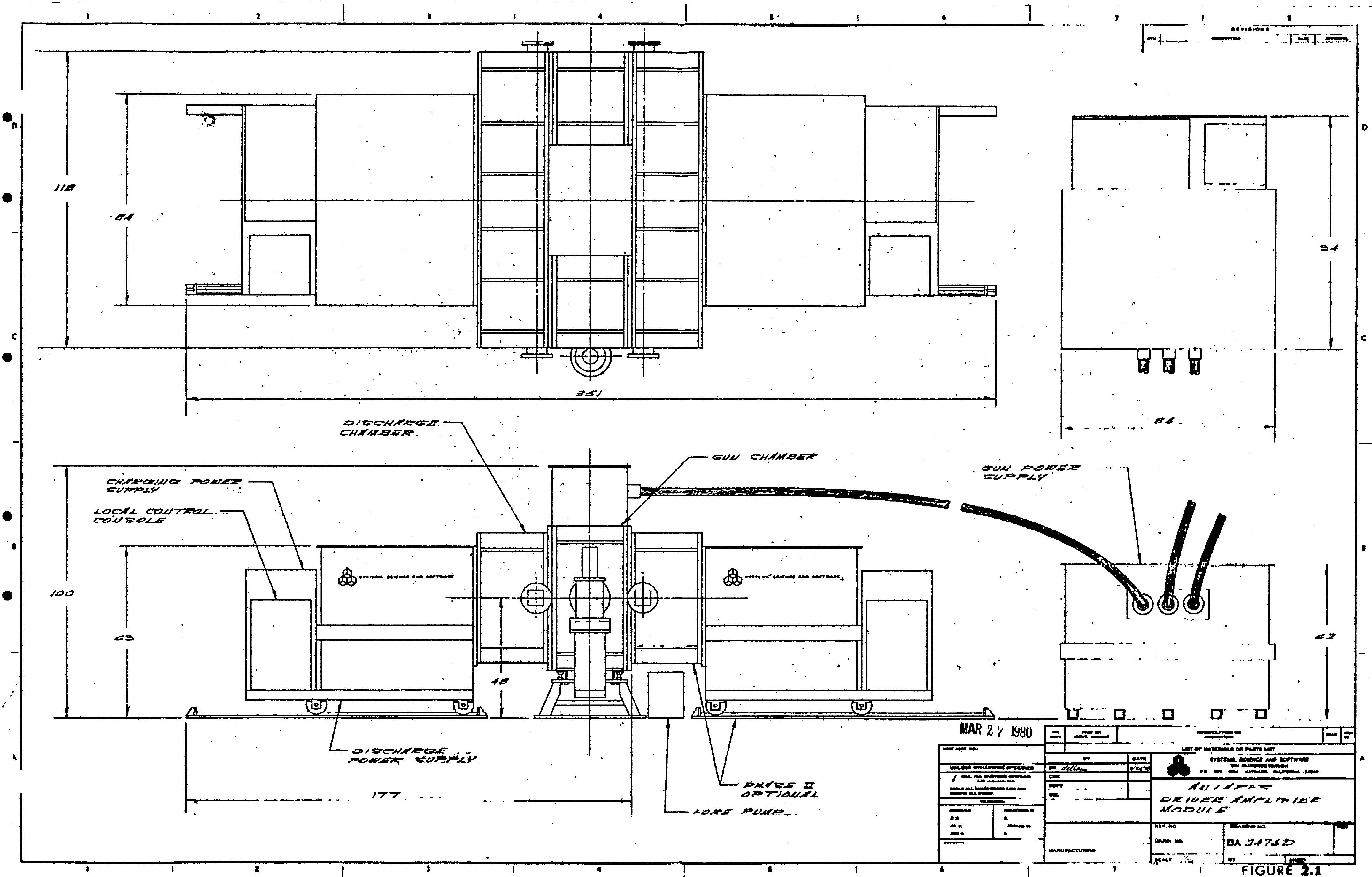









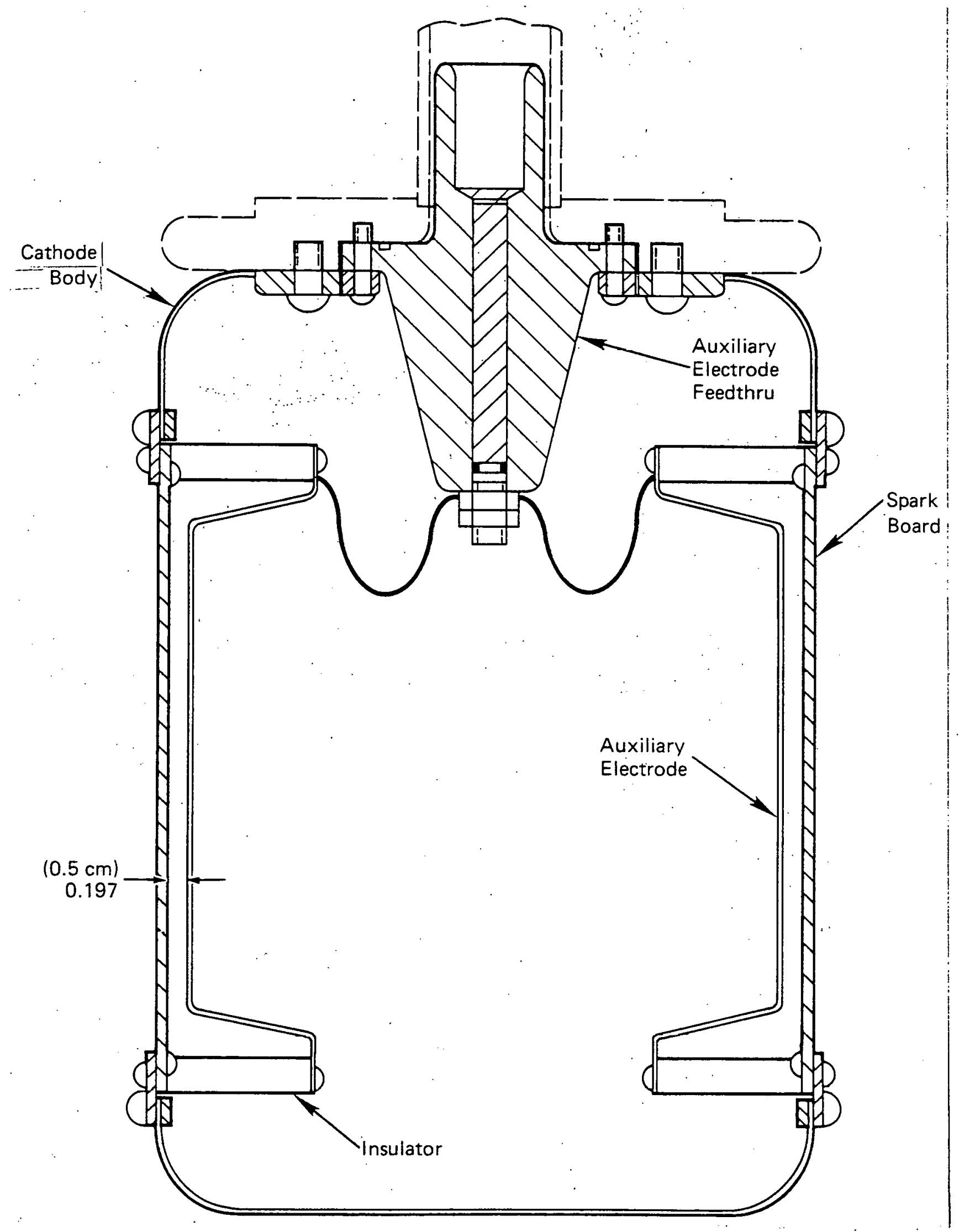

Fiqure 2.3. Driver Amplifier Spark Cathode Assembly 
a

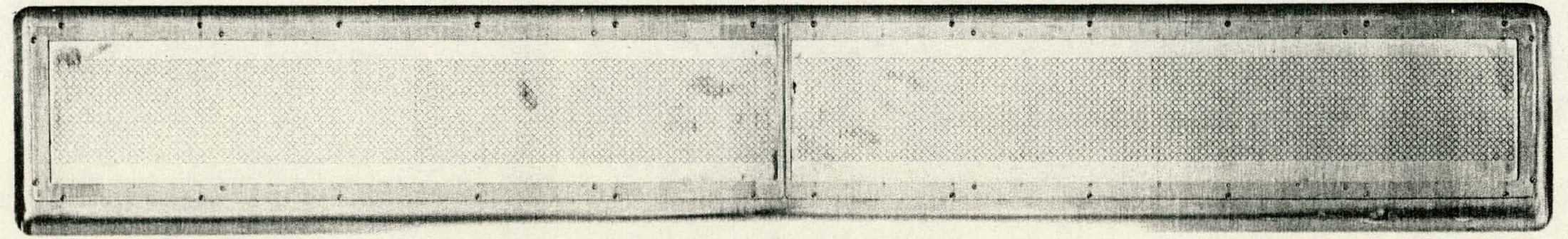

Figure 2.4. Cathode Assembly Spark Board View. 
Due to the relatively small area of the individual floating electrodes, or disks, and their distance to the grid structure, the capacitive coupling ratio of the disk between cathode and grid voltages is insufficient to guarantee surface flashover conditions. In other words, due to the extremely small disk to grid capacitance, the disk would be, in effect, at cathode potential. To increase the voltage difference between the disk and the cathode structure, an auxiliary electrode was added, $0.5 \mathrm{~cm}$ behind the spark boards. This electrode is shown in the drawing of Fig. 2.3. The auxiliary electrodes are connected by means of a cable and a feedthru, to capacitors in the peaking switch tank above the electron gun chamber. The auxiliary electrodes and connections to the feedthru are evident in Fig. 2.5, a photograph of the inside of the cathode assembly with one set of spark boards removed.

The relationship of the various spark cathode coupling capacitances is schematically represented in Fig. 2.6. Only one disk electrode is shown for simplicity. Although $\mathrm{C}_{4}$ could be bypassed in order to achieve a maximum $\Delta \mathrm{V}$ between the cathode and disk, the inevitable breakdown of the $0.5 \mathrm{~cm}$ gap would short-circuit the gun. Thus, $\mathrm{C}_{4}$ must be capable of withstanding full cathode potential.

Table 1 lists potential difference data obtained for several disk configurations. The column labeled $d_{\text {gap }}$ refers to the size of the surface insulation gap surrounding each disk electrode. Combining the above data with surface flashover data (Fig. 2.7) permits one to determine the appropriate distance to space the auxiliary electrode $(0.5 \mathrm{~cm})$ and the value for $\mathrm{C}_{4}$ $(1.25 \mathrm{nF})$. In this case, $\mathrm{C}_{4}$ consists of four, $0.005 \mu \mathrm{F}, 90 \mathrm{kV}$ capacitors in series. 


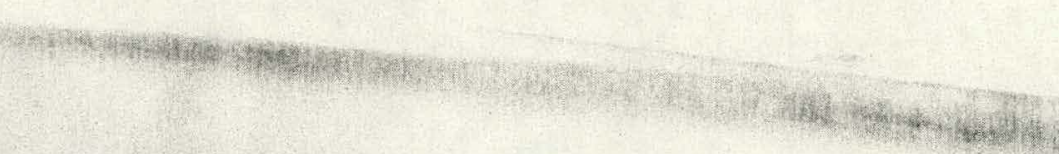

,
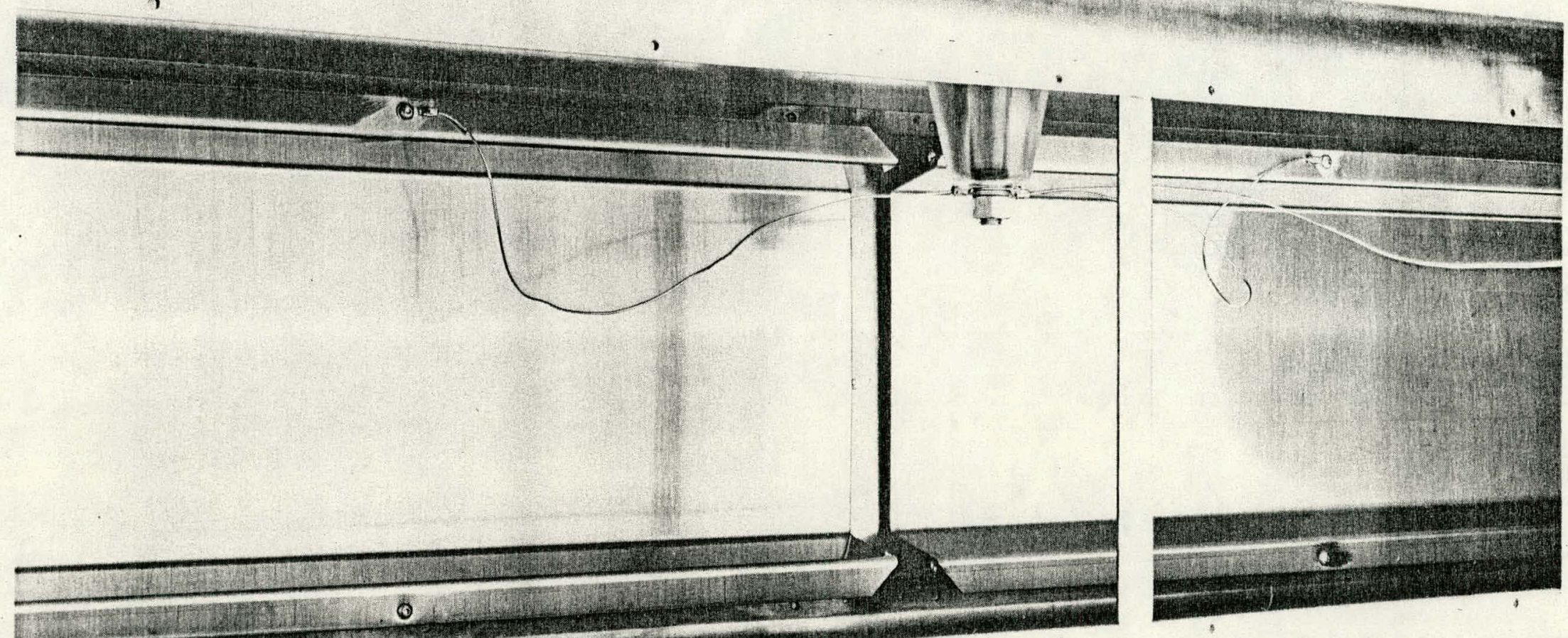

Mrther

nis.

-

- 


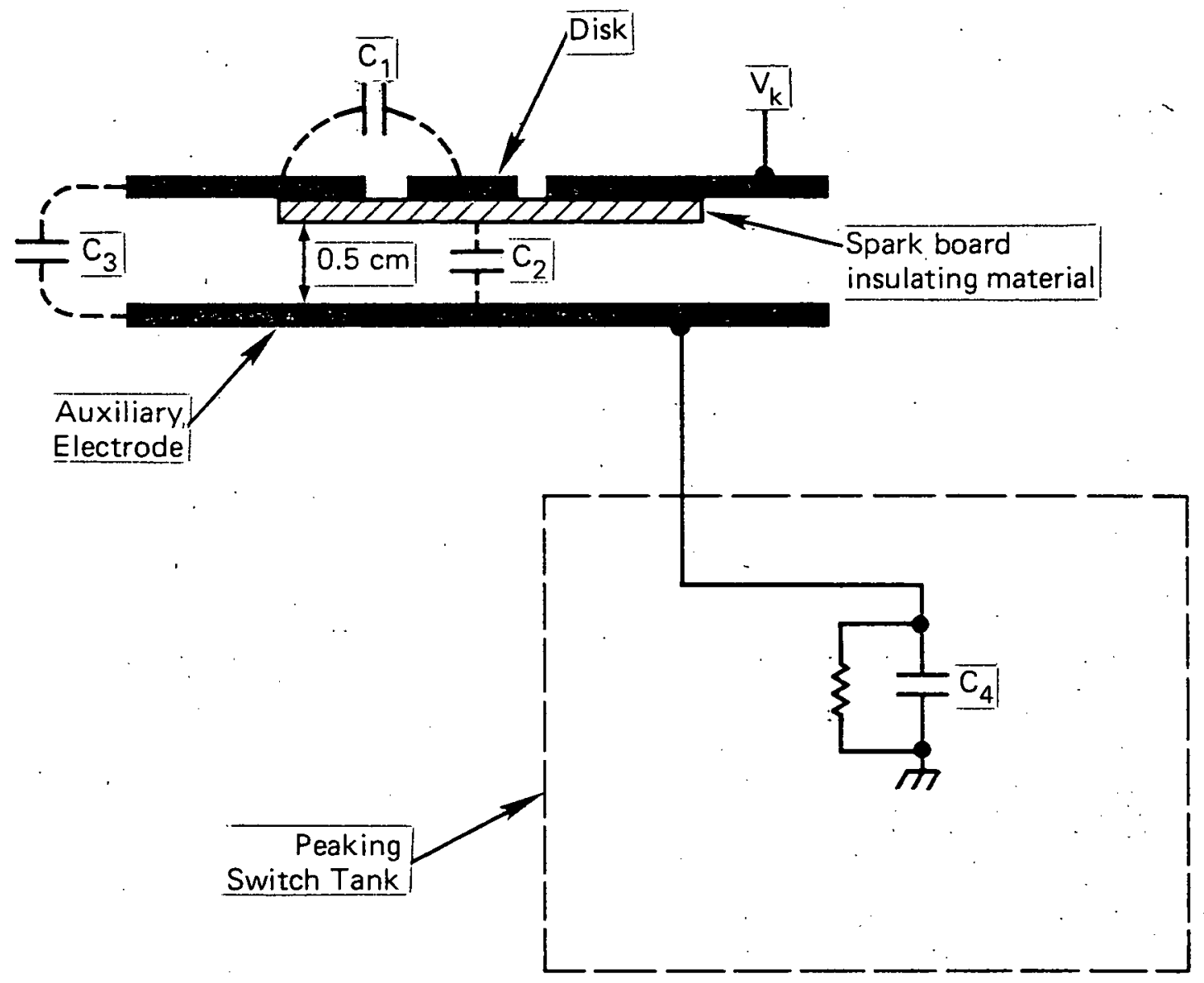

Figure 2.6. Spark Cathode Coupling Capacitances 


\begin{tabular}{|c|c|c|c|}
\hline \multicolumn{4}{|c|}{$5 \mathrm{~cm}$ anode cathode space } \\
\hline $\mathrm{r}_{\text {disk }}(\mathrm{cm})$ & $\mathrm{d}_{\text {gap }}(\mathrm{cm})$ & $\%$ voltage & $\Delta \mathrm{V}(\mathrm{kV})$ \\
0.5 & 0.10 & 0.989 & 2.75 \\
0.5 & 0.25 & 0.981 & 4.75 \\
0.5 & 0.50 & 0.968 & 8.00 \\
0.5 & 0.75 & 0.955 & 11.25 \\
1.0 & 0.50 & 0.953 & 11.75 \\
2.0 & 0.50 & 0.926 & 18.50 \\
2.0 & 1.00 & 0.888 & 28.00 \\
\hline
\end{tabular}

lable 2. 7. Lisk Potential for Different Geometries: 


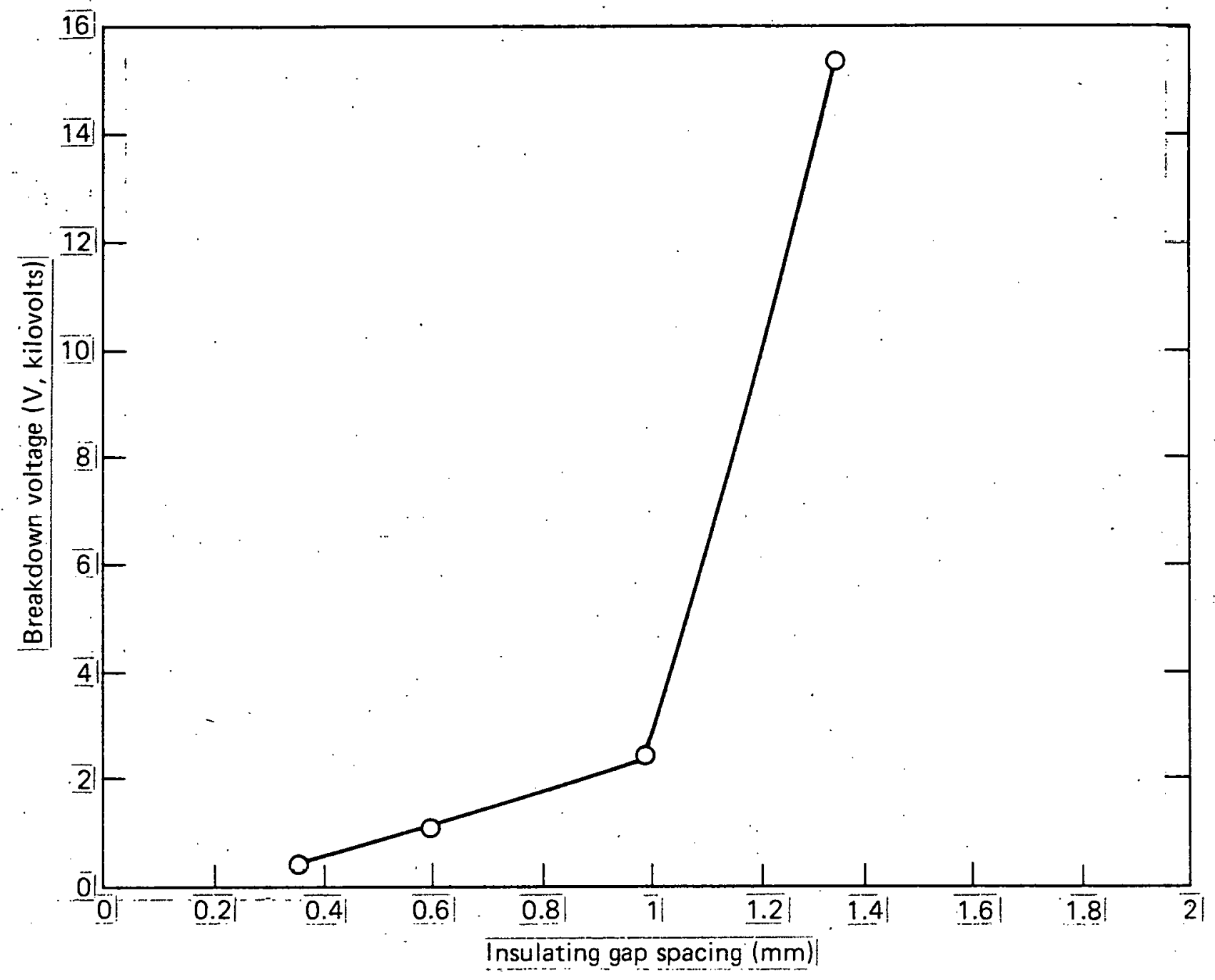

Fiyurv 2.7. Sulface Flashover Characteristic in Vacuum

II 


\section{SECTION 3}

TEST RESULTS

\section{Prototype Power Amplifier}

The spark cathode assembly for the Antares power amplifier prototype was designed to directly replace the blade emitter assembly. The expected benefit was to be primarily in terms of extended lifetime of the cold cathode emission surface. No dramatic short term difference in performance was anticipated.

The construction technique for the spark boards resembles printed circuit board fabrication. The spark electrode pattern is obtained by selectively etching material from copper overlaid, G-30 fiberglass/epoxy boards. 'In actual operation, these copper on fiberglass boards replace tantalum blades mounted in stainless steel holders. The higher outgas rate of the G-10 material under vacuum conditions imposes additional load upon the vacuum system. In the event that these outgas rates should prove unacceptable for larger area guns, such as the final design Antares electron gun, alternative substrate materials can be used in place of the fiberglass.

The insertion of the spark boards in the prototype electron gun vacuum vessel amounted to $\sim 6 \mathrm{~m}^{2}$ of fiberglass surface. The vacuum vessel, also containing two, large, epoxy, high voltage feedthru bushings, is pumped with a 10 inch diameter, water cooled baffle, oil diffusion pump. System vacuum following initial pump down matched readings obtained with blade cathodes $\left(\cdots 1 \times 10^{-5}\right)$ Torr.

A map of electron beam current density was produced using time resolved, Faraday cup collectors. Average transmitted current density during the test was $\sim 60 \mathrm{~mA} / \mathrm{cm}^{2}$. Readings were taken at the center and edge of the window at five different positions along the $130 \mathrm{~cm}$ length of the electron beam window. Fig. 3.la shows the difference in current density between window center and window edge for the five positions using spark cathodes. 


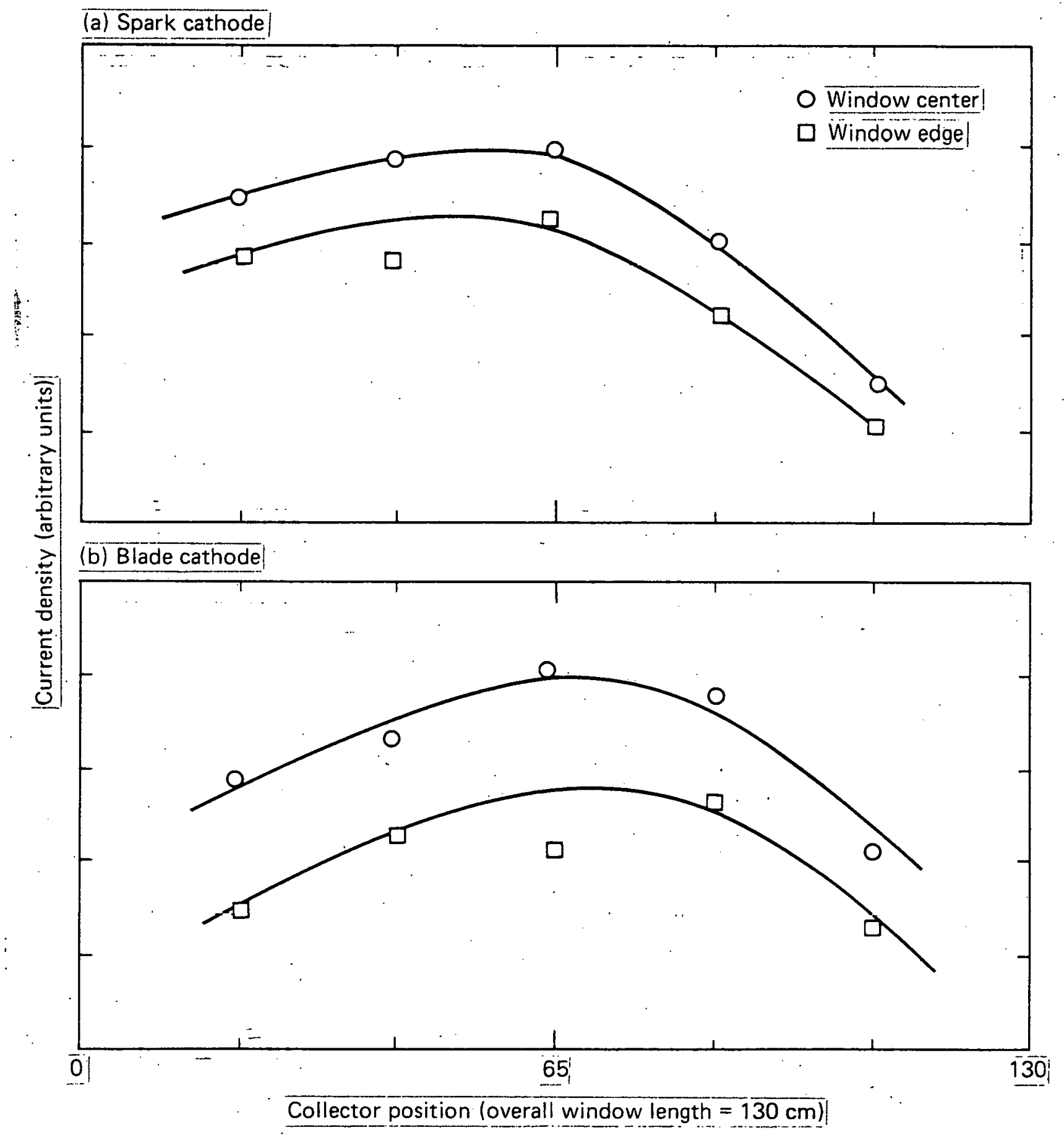

Figure 3.1. Comparison of Spark/Blade Current Density Distribution - Prototype Power Amplifier: 
Fig. 3.1b plots the equivalent data for blade cathodes. Note the improvement in edge to center current density ratio for the spark cathode. This is attributed to differences in field configuration, and hence electron trajectories, near the flat spark boards as contrasted to protruding blades. The depression of the current density signals on the right side of the data plots is due to magnetic deflection of electron trajectories caused by a single longitudinal cathode current feed.

Optical access ports into the electron gun chamber permitted open shutter photography of the spark cathode during operation. From examination of the photographs, it is evident that most, if not all, spark emission sites are active. Visual inspection of the spark board after approximately 250 shots confirmed the above. Successful emission site generation was even demonstrated when driving the cathode at only $250 \mathrm{kV}$, half of the normal operating voltage.

\section{Driver Amplifier}

Extensive testing of the driver amplifier electron gun operating with blade cathodes was performed under another contract prior to delivery of the unit to LASL. During the testing several difficulties with blade emitter operation in this system were experienced. The results may be summarized as follows:

1. Due to operation of the electron gun from a pfn source, use of a peaking switch to obtain the maximum $d V / d t$ was necessary. At best, this methode produces half of the cathode ignition voltage available from a striaght Marx driver circuit. Loss of blade emission of ten occurred after less than 100 shots.

2. The geometry of the cathode assembly, the grid structure and the electric field configuration between them resulted in electron "optics" which caused the electron beam to overfill the transmitting surface of the grid, unacceptably decreasing gun efficiency and increasing the necessary cathode current to produce the required electron beam density. 
3. Attempts to correct item 2 by increasing the effect of the cathode focusing electrode amplified problems in cathode ignition arising from the conditions. described in item 1.

Spark board cathodes as an electron emission source have the potential to overcome all of these difficulties. The approach and results are described in the following paragraphs.

Initial operation of the driver amplifier with a spark cathode assembly was intended to demonstrate the capability for elimination of the peaking switch. The switch was operated under three conditions: 50 psia of air in the switch (normal for blade cathode), 12 psia in the switch, and switch shorted. Successful ignition of the spark cathode resulted in each case, however, electron gun impedance stability was greatest when the switch was shorted or operated at very low pressures (see Fig. 3.2). All further testing was performed without the peaking switch.

Electron gun voltage and current waveforms were obtained to compare overall gun behavior to similar data from blade cathode test results. A key feature was the marked improvement in the ratio of grid current $\left(\mathrm{I}_{\mathrm{g}}\right)$ to total cathode current $\left(\mathrm{I}_{\mathrm{k}}\right)$. The results are plotted in Fig. 3.3 as a function of time. Two features are of interest: the improvement in the ratio of $I_{g}$ to $\mathrm{I}_{\mathrm{k}}$, and the reduced variation in that ratio. The former increases the total electron gun efficiency and the latter indicates improved grid control for stable gun operation.

Analysis of the magnitude of the ratio $\mathrm{I}_{\mathrm{g}} / \mathrm{I}_{\mathrm{k}}$ for the two cathodes, combined with knowledge of the cathode and grid geometry, can be used to estimate the spread of the electron trajectories upon traversing the cathode to grid space. The minimum current ratio obtainable would be 0.2 , reflecting the $80 \%$ transmission of the open grid structure. Ratio values higher than this result from the electron beam impinging on the nontransmitting regions of the grid structure. 


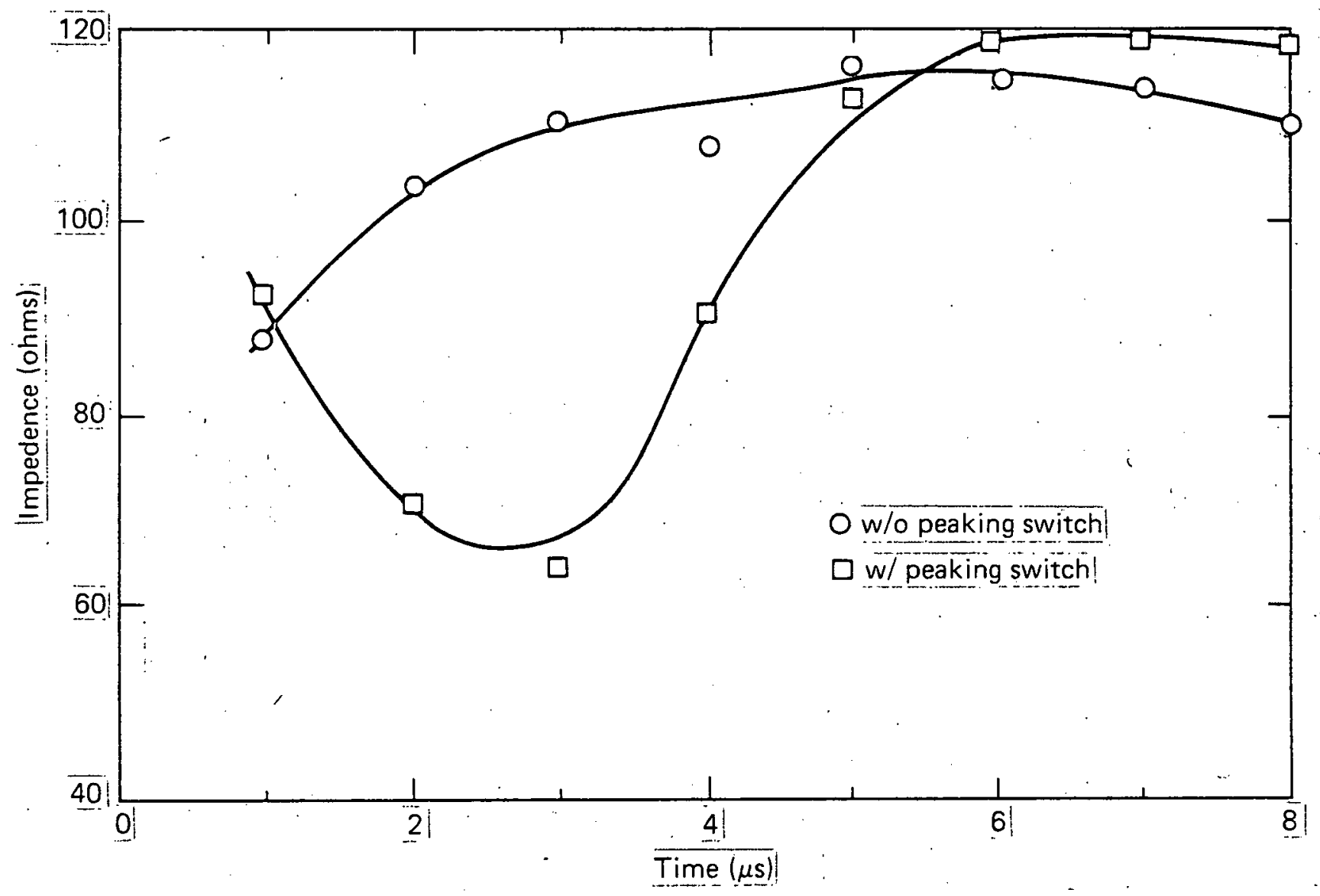

Figure 3.2. 'Impedence vs. Time History - Spark Cathode in Grid Controlled Gun| 


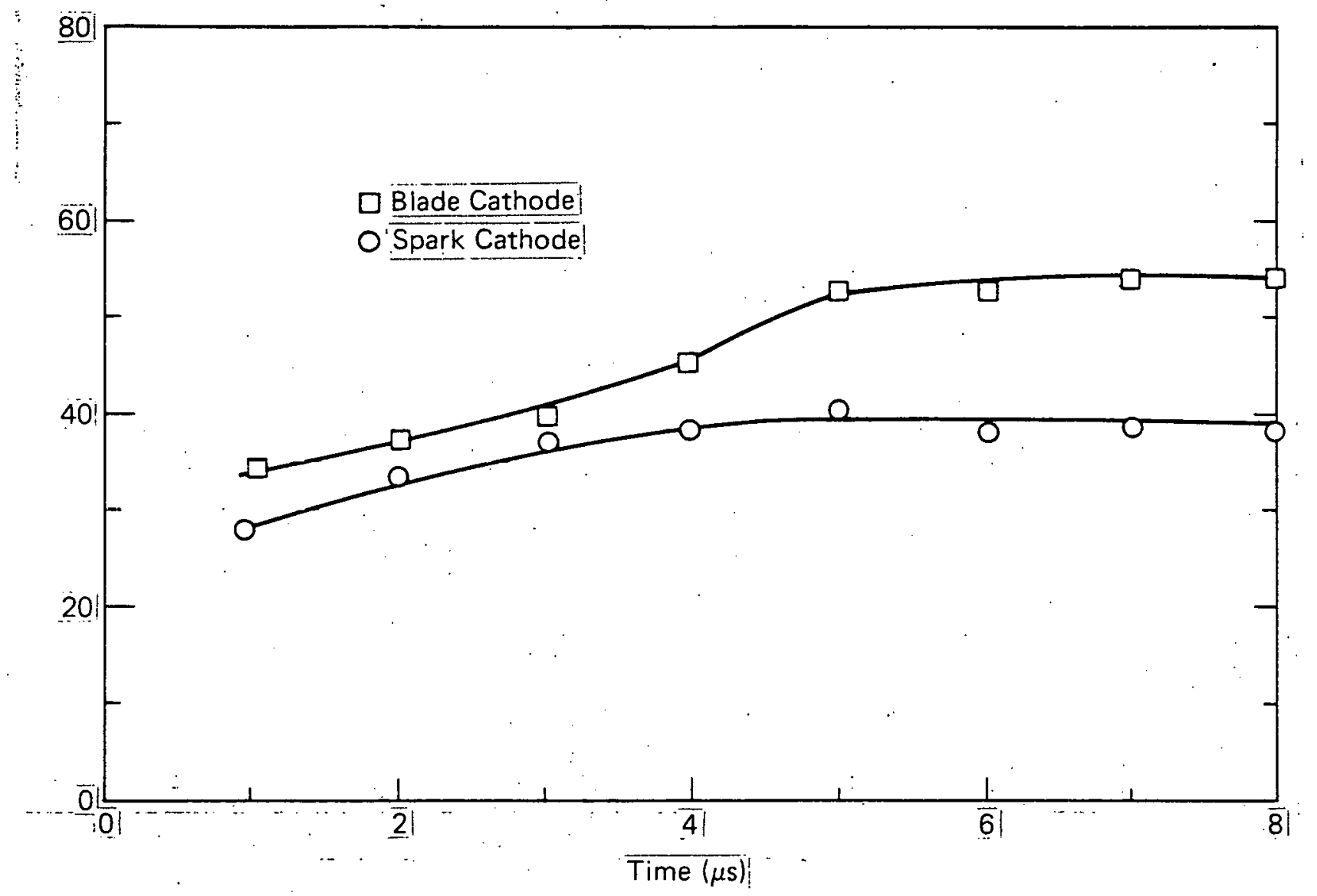

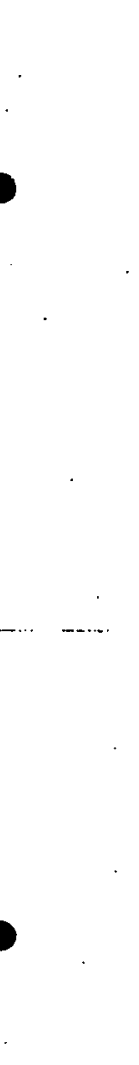

Figure 3.3. $i_{G} / i_{k}$ vs. Time for Blade and Spark Cathode 
The total cross sectional area (A) of the electron beam at the grid may be estimated by solving the following equations, remembering that the gun is dual-sided:

1) $\mathrm{J} \times \mathrm{A}=\mathrm{I}_{\mathrm{k}}$

2) $\left(0.2 \times J \times A_{1}\right)+\left(J \times A_{2}\right)=I_{g}$

3) $A_{2}=A-A_{1}$

Where:

$\mathrm{J}=$ electron beam current density at the grid

$A=$ cross sectional area of the electron beam at the grid

$A_{1}=$ area of the transmitting portion of the grid

$\mathrm{I}_{\mathrm{k}}=$ total cathode current

$I_{g}=$ total grid current

Note that if $A_{2}=0, I_{g}$ would be $20 \%$ of $I_{k}$, the optimum result for maximum efficiency attainable with an $80 \%$ transmitting grid. $A_{2}$ thus reflects the undesired amount of beam blowup. By relating the value of $A$ to the cathode to grid spacing and the active area of the cathode, an approximate value for the spread in electron trajectories may be obtained. Performing this calculation for data from both blade cathode and spark cathode experiments yields the following beam spread, measured by angle from the cathode normal: blade cathode, $45^{\circ}$; spark cathode, $35^{\circ}$.

These results are not surprising. In the case of the blade cathode, the emitter protrudes roughly $2.5 \mathrm{~cm}$ from the main cathode structure. The cathode structure incorporates a shaped focusing electrode to prevent even greater beam spread (see Fig. 2.2). The angle obtained for the flat, spark cathode, emitting surface agrees well with planar, Pierce type, electron gun theory. These studies predict a $36^{\circ}$ deviation from rectilinear electron trajectories.

The control of emission site location inherent in the design of the spark cathode, coupled with some knowledge of the electron trajectories, suggests a modification to the present driver amplifier cathode design. The 15 rows of active emissions sites in the vertical dimension produce an electron beam with roughly twice the required $17 \mathrm{~cm}$ height. 
A large efficiency penalty is paid in current loss to the grid and in edge effect loss at the anode aperture. By reducing the active area of the cathode to no more than three rows while retaining the $35^{\circ}$ trajectory divergence characteristics, nearly a factor of two increase in efficiency is attainable as shown in Table 3.l. Corresponding values for the blade cathode are included for comparison.

A detailed map of the electron beam current density was performed using Faraday cup collectors. Each collector viewed a $2 \mathrm{~cm}$ wide by $15 \mathrm{~cm}$ high portion of the transmitted beam. A total of 50 positions were monitored along the 2 meter length of the gun for both spark cathode and blade cathode operation. The data are presented in Figs. 3.4 and 3.5. The most obvious feature is the low current density measured just off center in the spark cathode case. This was primarily attributed to a lack of emission from one area of the spark board. Pressing schedule requirements for driver amplifier operation limited the spark cathode test period to less than one week. It is felt that the apparent emission loss can be further examined and readily corrected during a later test date.

Shot to shot current density signal reproducibility during the testing with the blade cathode varied by $30 \%$ while the spark cathode approached 10\%. The somewhat random nature of emission site generation with blade edge emitters is probably responsible.

The spark board outgas rate posed noproblems for the dirver amplifier vacuum system. Typical chamber vacuum achieved during blade cathode operation is $2 \times 10^{-6}$ Torr with a 10" 'diameter, oil diffusion pump. After an initial 36 hours under vacuum, chamber pressure for the spark cathode was $3 \times 10^{-6}$ Torr. Subsequent cycling of the chamber to air for over one hour followed by one hour under vacuum produced no degradation in chamber vacuum. 


\begin{tabular}{|c|c|c|c|}
\hline $\begin{array}{l}\text { Relative } \\
\text { Transmission }\end{array}$ & $\begin{array}{l}\text { Original } \\
\text { Spark Cathode }\end{array}$ & $\begin{array}{l}\text { Modified } \\
\text { Spark Cathode }\end{array}$ & $\begin{array}{l}\text { Blade } \\
\text { Cathode }\end{array}$ \\
\hline Grid opening & 0.8 & 0.8 & 0.8 \\
\hline Grid edge effect & 8.8. & 1.0 & 8.? \\
\hline Foil window support (anode) & 0.8 & 0.8 & 0.8 \\
\hline Anode edge effect & 8.6. & 0.9. & 8.6. \\
\hline Foil window ripstop & 0.8 & 0.8 & 0.8 \\
\hline Foil window (titanium) & 0.95 & 0.95 & 0.95 \\
\hline Discharge cathode & 0.8 & 0.8 & 0.8 \\
\hline Resultant efficiency & $19 \%$ & $35 \%$ & $16 \%$ \\
\hline
\end{tabular}

Table 3. 1. Electron Beam Transmission Efficiencyi 


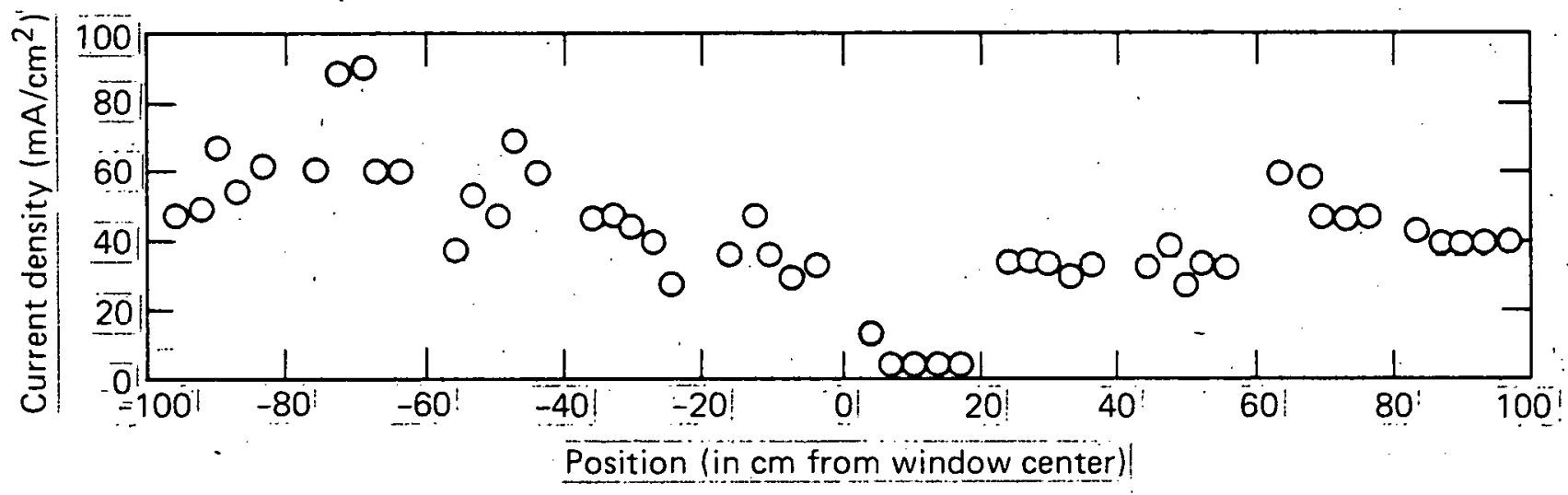

Figure 3.4. Electron Beam Current Uensity Distribution - Spark Cathode 


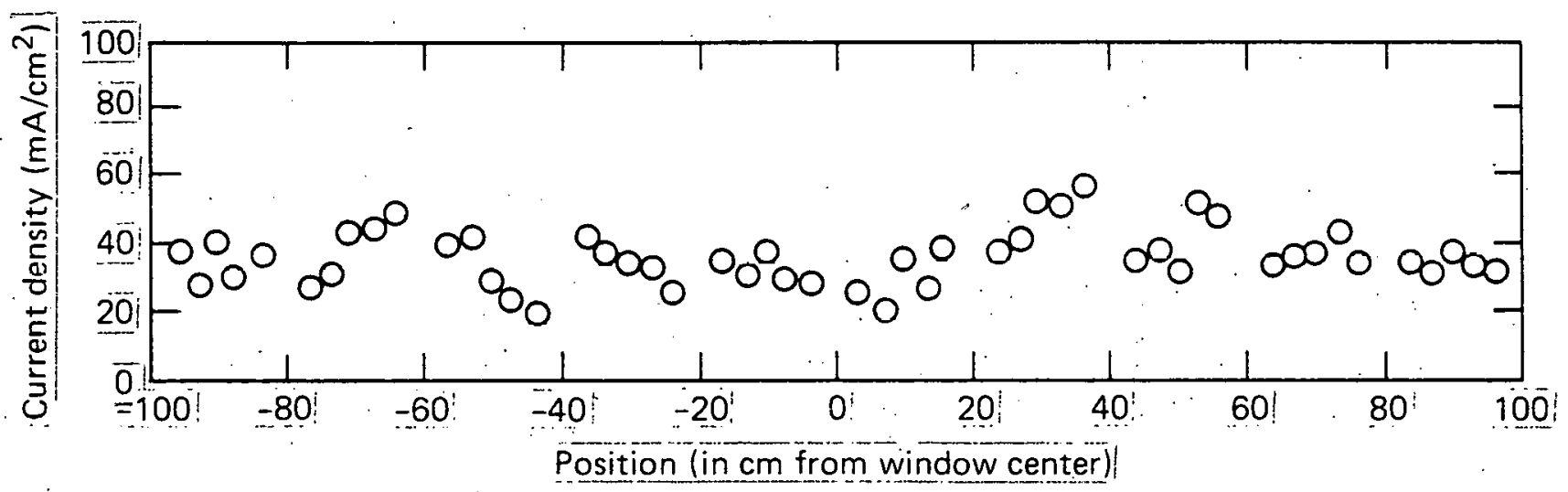

Figure 3.5. Electron Beam Current Density Vistribution - Blade Cathode: 


\section{SECTION 4 CONCLUSIONS}

\section{Power Amplifier Prototype}

The successful results from evaluation tests combined with relative ease of assembly make the spark cathode a serious candidate for installation and further testing on the first Antares power amplifier electron gun. Uncertainty with regard to satisfactory blade cathode ignition and performance in a gun three times the length of the prototype is a serious concern.

\section{Driver Amplifier}

Evaluation of limited testing performed to date reveals the spark cathode potential for significantly improving dual-sided electron gun performance. Further implementation of spark cathode technology for this program rests on the availability of additional test time to address the remaining issues, and to optimize the cathode configuration. 
APPENDIX A

PHASE I - FINAL REPORT 
TABLE OF CONTENTS

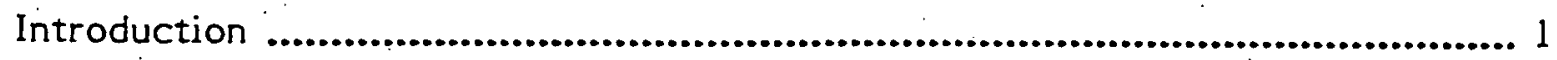

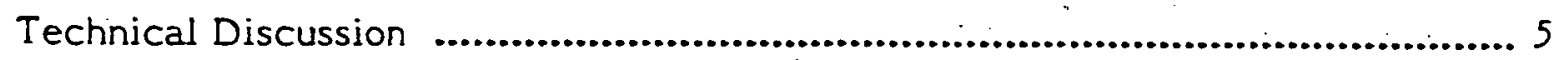




\section{LIST OF ILLUSTRATIONS}

Figure 1 A transverse section of the Antares prototype amplifier

Figure 2 Surface flashover characteristic in vacuum

Figure 3 Schematic representation of the capacitively isolated multiple spark source cathode

Figure 4 Spark cathode design

Figure 5 Alternative spark cathode design

- Figure 6 Equipotential mapping-electrode fixedat grid voltage

Figure 7 Equipotential mapping-electrode fixed at cathode voltage

Figure 8 . Electrolytic test tank 


\section{INTRODUCTION}

This report covers the first phase of a two phase program entitled "Development of Spark Cathode Electron Guns for the $\mathrm{CO}_{2}$ Laser Fusion Program" (SSS-P-78-84100-85). The requirements leading to the need for such a development are briefly reviewed, followed by a technical discussion of the first phase efforts.

With carbon dioxide laser systems becoming larger and more complex due to the continuing sophistication of laser fusion studies, the need for reliable component operation increases. A large stride forward was accomplished three years ago with the replacement of the hot cathode electron gun with a cold cathode unit. However, even the routine maintenance of a single electron gun unit, such as used in the Los Alamos Scientific Laboratory (LASL) Antares laser power amplifiers, will likely require a two day turn-around penalty.

The projected lifetime for the Antares system is 10,000 shots, but experiences from devices at LASL and elsewhere demonstrate a deterioration in beam uniformity by the 1000 shot level. The beam uniformity of these large area electron guns depend upon:

- The generation of a significant number of well distributed electron emission sites.

- The electron "optics" - electric and magnetic field configuration.

- The condition of the emitting surfaces.

Blade cathodes feature somewhat random site generation and a decrease in site density with use. As the cathode blades "age", the changes in the microstructure of the emission edge degrade their performance, resulting in the necessity of periodic blade replacement. 
The requirement for long lifetime and beam uniformity is one of reproducibility. If this requirement can be satisfied, the need for routine maintenance of the LASL electron guns no longer involves the cathode structure and reduces to insuring the vacuum integrity of the electron beam transmission windows.

In addition to reproducibility considerations, the Antares laser project staff expressed an interest in expanding the possible range of electron gun operating voltages from $450-500 \mathrm{kV}$ to $300-500 \mathrm{kV}$. This interest was generated as a means of improving the laser gain uniformity for the particular pumping volume geometry utilized in the Antares power amplifiers. The intention was to extend the voltage range without modifying the mechanical structure of the gun, i.e., by merely changing the energy storage system parameters. Operation of a $500 \mathrm{kV}$ designed blade cathode at only $300 \mathrm{kV}$ intensifies the previously mentioned problems in achieving lifetime, repeatability and beam uniformity.

To achieve the desired cathode performance characteristics the San Francisco Division of Systems, Science and Software (S-Cubed) designed and constructed a spark cathode assembly suitable for test and evaluation in the Antares prototype power amplifier electron gun. Figure 1 is a transverse section of the prototype power amplifier including the cathode, a 12 section cylindrical assembly, approximately $75 \mathrm{~cm}$ in diameter by $1.3 \mathrm{~m}$ in length.

Following computer design calculations and low voltage modeling, S-Cubed built a 12 sided spark cathode configuration for use in the LASL prototype. The assembly was received at LASL in October, 1978. The frontispiece shows the spark cathode assembly just prior to shipment.

A life test was performed on a small section of the large spark cathode array at $S$-Cubed to determine the projected reliability of the specific design. After being subjected to 10,000 pulses, the design point for Antares; no discernible deterioration had occurred. The cathode section was then returned to life testing to obtain a 100,000 shot history. Again, no significant deterioration in performance occurred. 


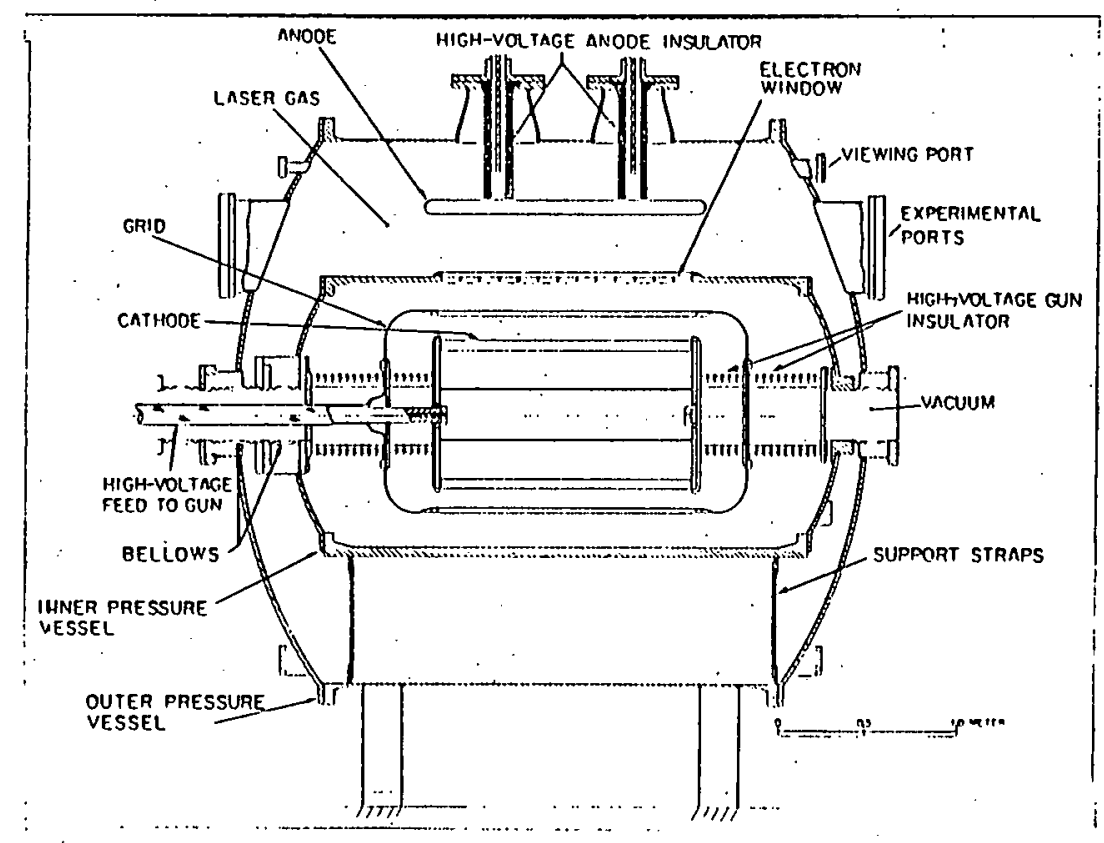

Figure 1 A transverse section of the Antares prototype amplifier 


\section{TECHNICAL DISCUSSION}

The ultimate success of a cold cathode for electron gun operation lies in its ability to generate specific electron emission site locations and to protect these sites from degradation in use. Blade cathodes require an electric field near a sharp edge in a vacuum, to create the plasma source for electrons. This plasma production: is the first phase of the vacuum breakdown process. The voltage supplied to the cathode and the electrode spacing are generally determined by the specific beam parameters required, rather than to create optimum conditions for emission śite initiation.

In contrast to this, spark cathodes utilize a breakdown plasma along insulated surfaces at the cathode as a source of electrons. With proper design of the electrodes and the surface spacing, breakdown can be readily achieved at voltages small compared to the total cathode voltage. Figure 2 details the voltages necessary for breakdown to occur on surfaces for small gaps. The cathode structure takes the form of an array of electrically isolated (floating) electrodes distributed on a surface which includes a cathode frame. As voltage is applied to the cathode frame, capacitive coupling between each floating electrode and the anode causes a voltage differential to occur between the electrode and the cathode frame (Figure 3). When the surface flashover potential is exceeded, breakdown occurs and the associated plasma is the source for further cold cathode emission. The occurrence of sparks between the cathode and the floating electrodes does not destroy the voltage differential established by the unsparked electrodes. Eventually all electrodes will spark, leading to precise geometric control of emission site density. 
S-Cubed has thus developed what appears to be a cathode assembly which gives precise control of emission site location for beam uniformity and which has a lifetime far in excess of present laser fusion program requirements. 


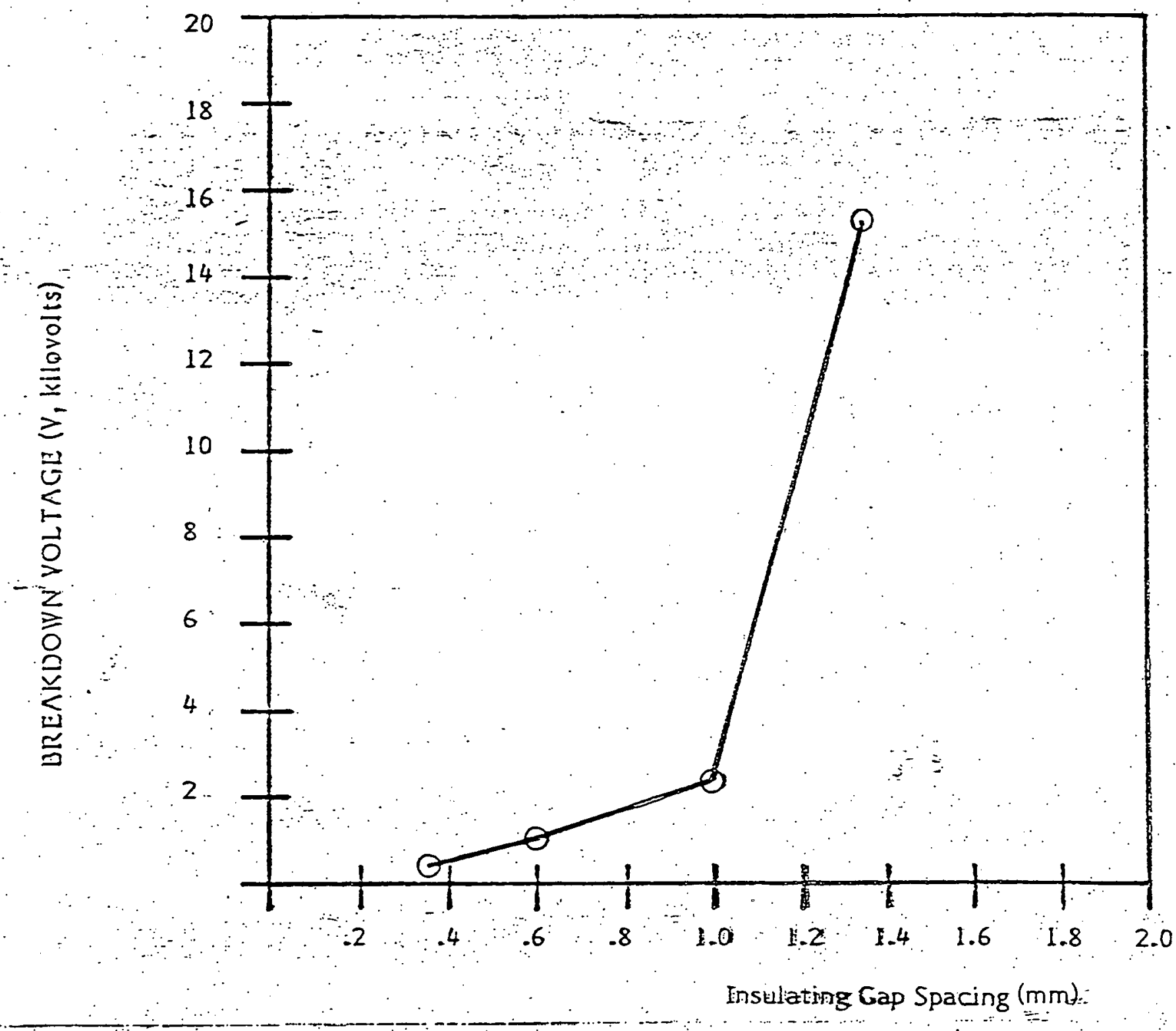

Figure 2 Surface flashover characteristic in vacuum

$\therefore \quad \therefore \quad A-8$




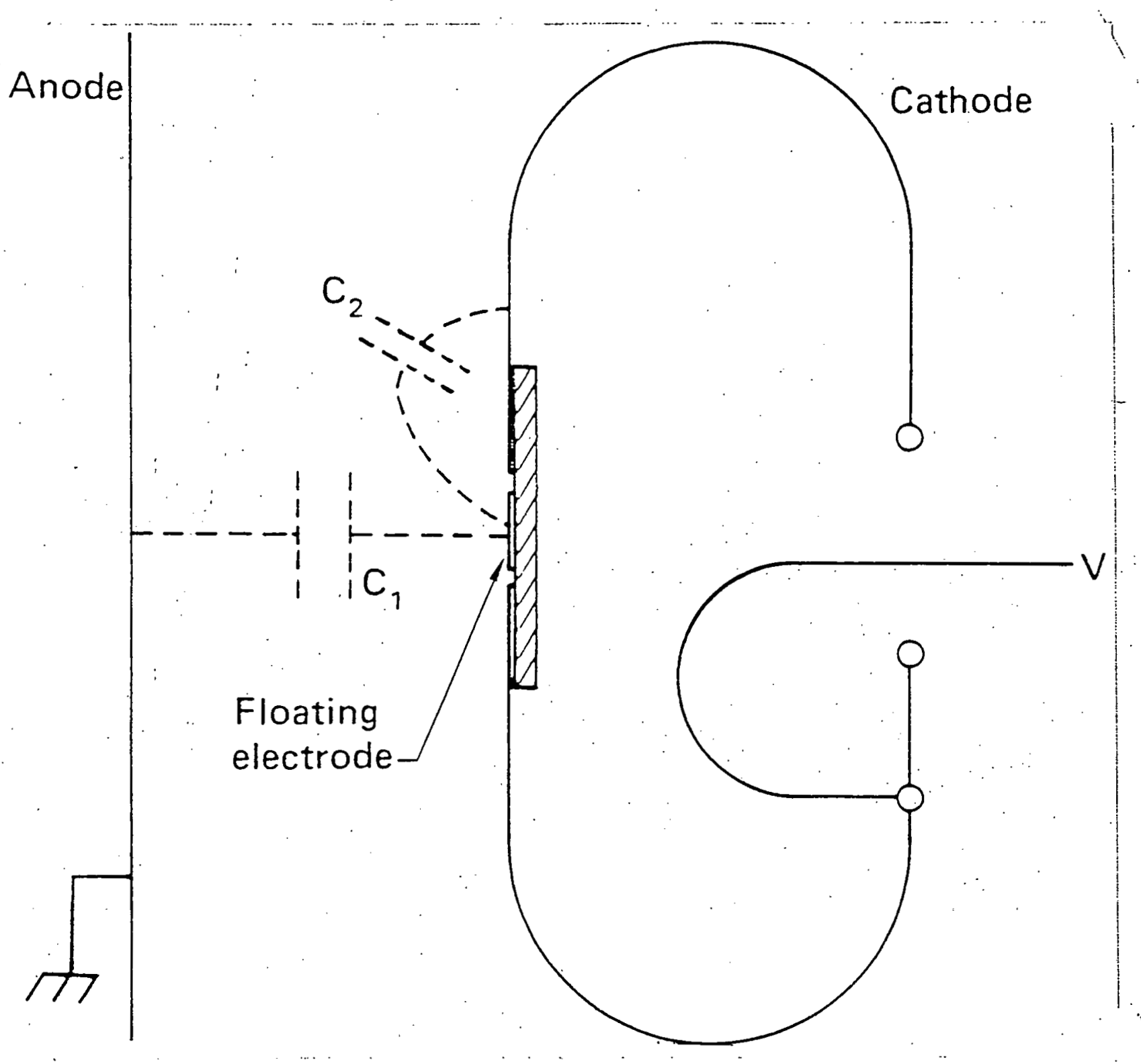

Figure 3 Schematic representation of the capacitively isolated multiple spark source cathode 
Two specific spark cathode designs were constructed for the Antares prototype power amplifier. The first has $5 \mathrm{~cm} \times 7.5 \mathrm{~cm}$ floating electrodes spaced between frame rails at cathode potential. Figure 4 , is a photograph of a section of the cathode assembly. The gap where the spark is created is approximately $0.7 \mathrm{~mm}$ and the sites are distributed at a linear density of 20 per meter. The cathode is constructed by etching a copper-clad printed circuit board. The insulating material is $\mathrm{G}-30$ fiberboard.

An alternative cathode design is shown in Figure 5. The "buttons" in the photo are tied to the cathode potential. The primary difference between the two designs lies in the electric field configurations surrounding the floating electrodes. The alternative design should provide additional defocussing of the electron beam for improved beam uniformity. One such cathode section was supplied to LASL for comparative evaluation.

For design of the spark cathodes, it was necessary to determine the potential difference generated between the cathode and the floating electrodes. This has been accomplished by determining the relative capacitance values between the electrode and anode (grid), and between, the electrode and the cathode. The magnitude of the capacitances was obtained by solving pairs of Laplace's equations for two cases:

1. The floating electrode fixed at ground (or grid) voltage.

2. The floating electrode fixed at cathode voltage.

Figures 6 and 7 , respectively, show the equipotential mapping created from the computer generated solution for. the Antares geometry. Integrating the normal electric field yielded the charge on the electrode for the two cases. The capacitances were proportional to the charges at fixed voltages. Knowing the capacitances, the floating potential was calculated directly. The method may be summarized as follows: 


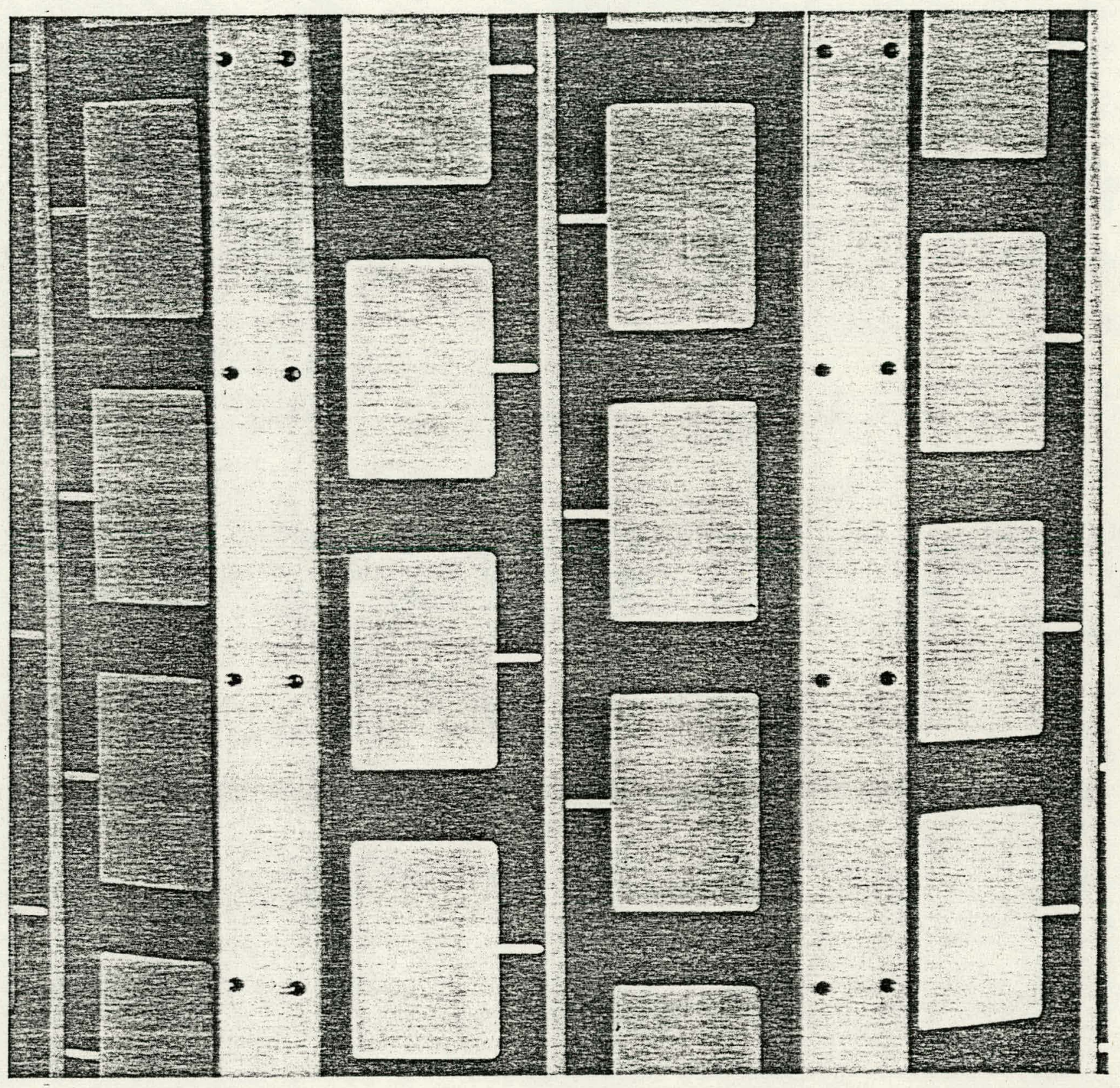

Figure 4 Spark cathode design 


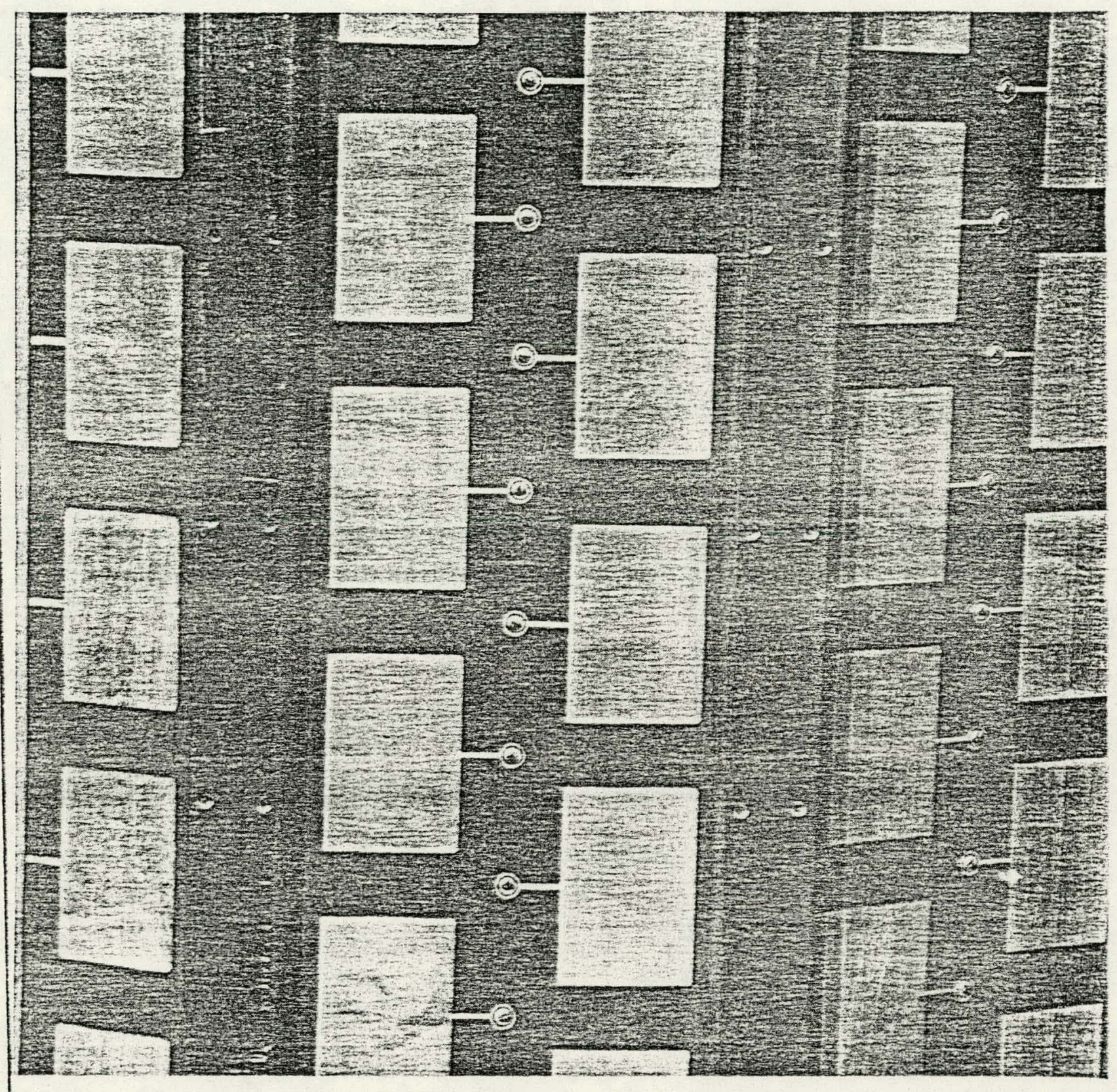

Figure 5 Alternative spark cathode design 


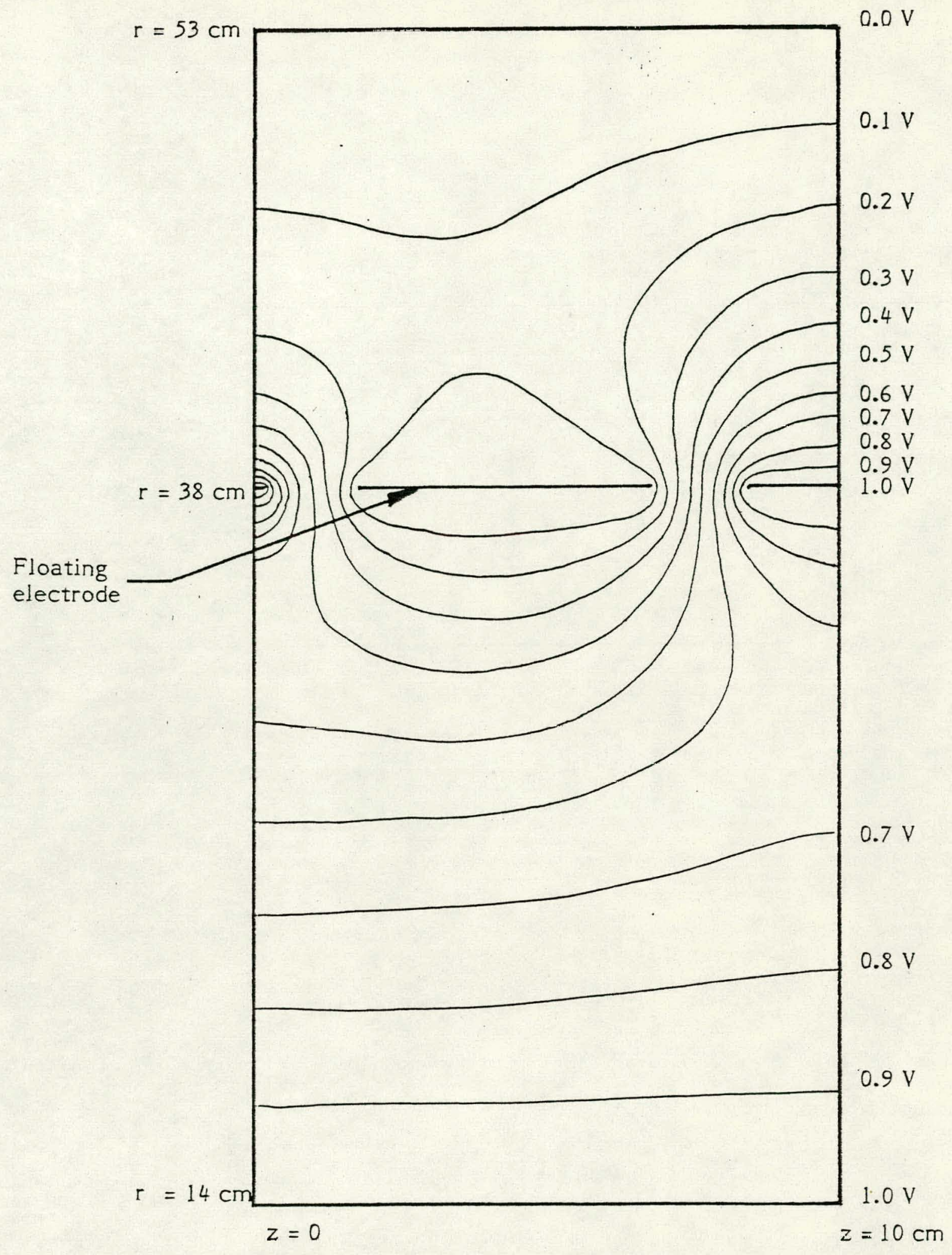

Figure 6 Equipotential mapping - electrode fixed at grid voltage 


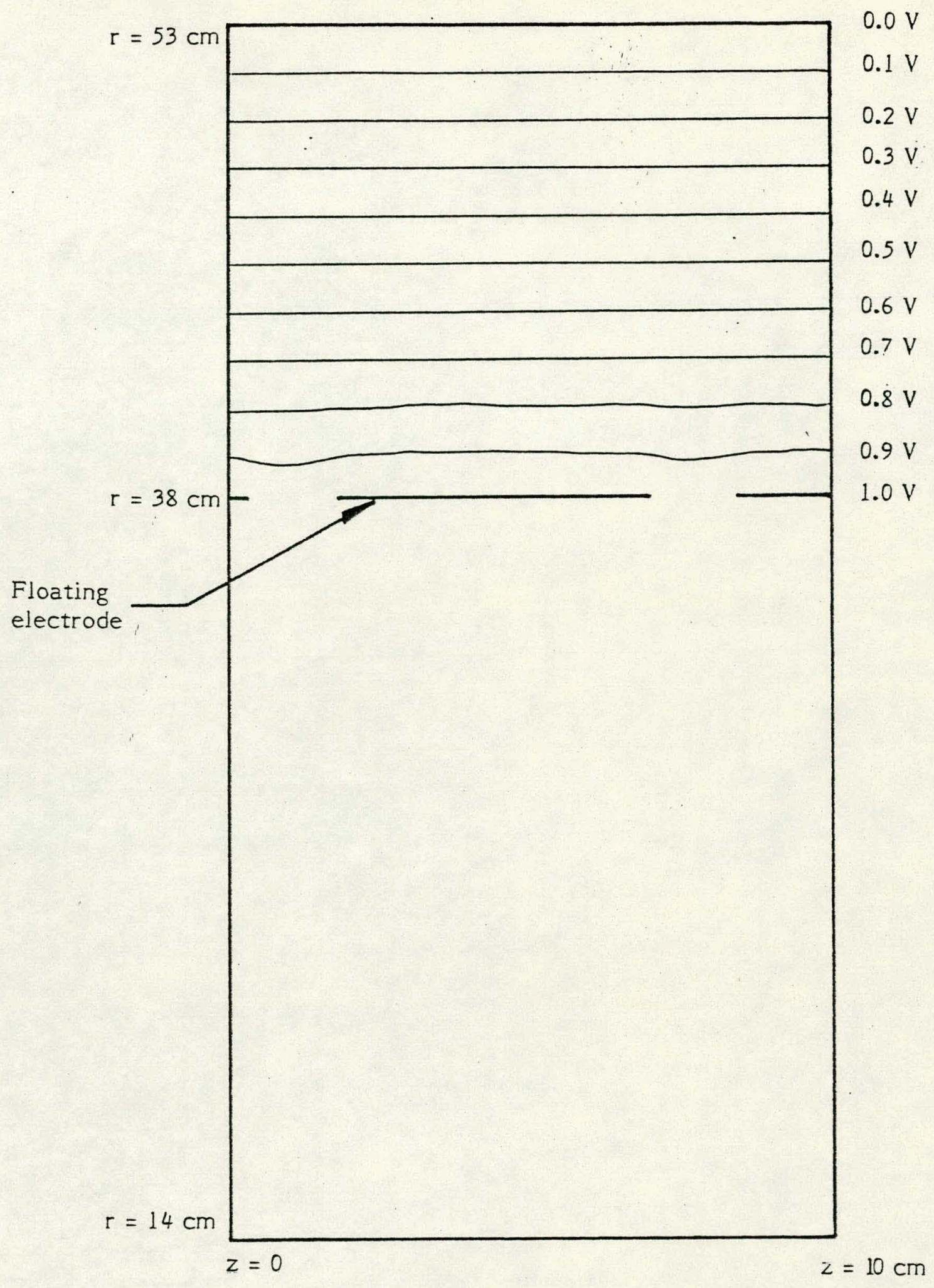

Figure 7 Equipotential mapping - electrode fixed at cathode voltage 
a) Equivalent Circuit for the Electrostatic Problem

Floating electrode

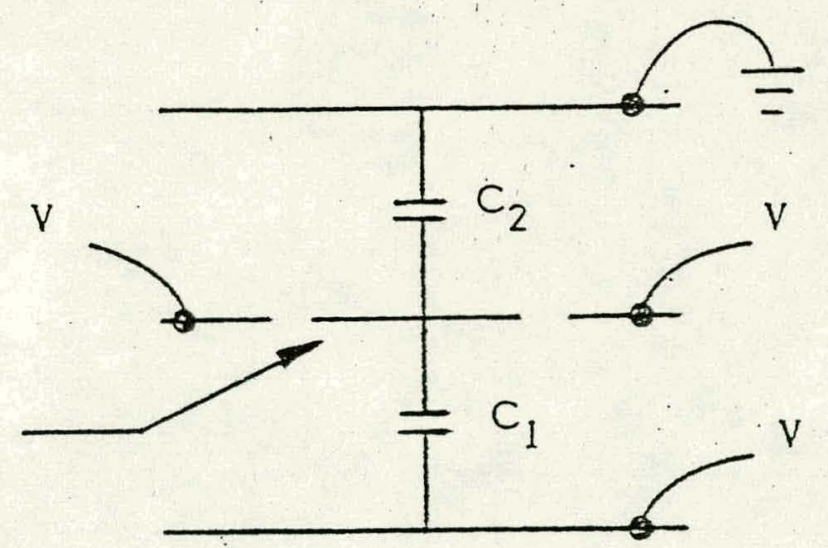

b) Determination of Relative Capacitances

Case 1 - Electrode fixed at ground voltage

$$
c_{1}=Q_{1} / \Delta V_{1}
$$

Obtain $Q_{1}$ from integration of the normal electric field Case 2 - Electrode fixed at cathode voltage

$$
C_{2}=Q_{2} / \Delta V_{2}
$$

Obtain $Q_{2}$ from integration of the normal electric field

C) To find the floating potential then

$$
\begin{gathered}
C_{1}\left(V_{f}\right)+C_{2}\left(V_{f}-1\right)=Q_{\text {total }}=0 \\
V_{f}=\frac{C_{2}}{C_{1}+C_{2}}
\end{gathered}
$$

The Antares electron gun uses a control grid referenced to ground through a resistor. During the turn-on phase, this grid capacitively divides between cathode and ground potential and acts as the effective anode shown in the calculations. The calculations predict the floating electrode will attain $78 \%$ of the cathode to grid voltage, establishing a flashover condition before the cathode reaches $20 \mathrm{kV}$. 
An experiment was performed as an alternative means of determining the floating potential. A full scale Antares prototype cathode mock-up with a representative grid structure was immersed in an electrolytic solution. Alternating current voltages between 10 volts and 75 volts were applied to the cathode with the grid grounded. Voltage on a single floating electrode was monitored both with an oscilloscope and a digital voltmeter. In all cases, the floating potential achieved $\sim 20 \%$ differential to the cathode voltage. Measurements were also made with all the floating electrodes shorted to the cathode, save one. This approximated the condition of all but one electrode sparked. Results indicate an $11 \%$ voltage differential still existed, sufficient to create flashover. These results agreed well with the previous calculations. The experimental set-up is shown in Figure 8.

A life test was performed at S-Cubed on a partial section of the spark cathode designed for LASL. Two emission sites were subjected to 10,000 shots of $100 \mathrm{kV}, 10$ amps emission current per site, and $\sim 3 \mu \mathrm{sec}$ duration pulses. These parameters reflected the cathode to grid operating conditions to be encountered in the Antares system. Inspection of the spark cathode and monitoring of current and voltage waveforms revealed no deterioration of the electrodes. Life testing was continued to 100,000 shots, 10 times the design lifetime for Antares. Cathode performance continued to be reliable and highly reproducible. Consequently, spark cathode lifetimes for LASL fusion lasers should exceed system requirements. 


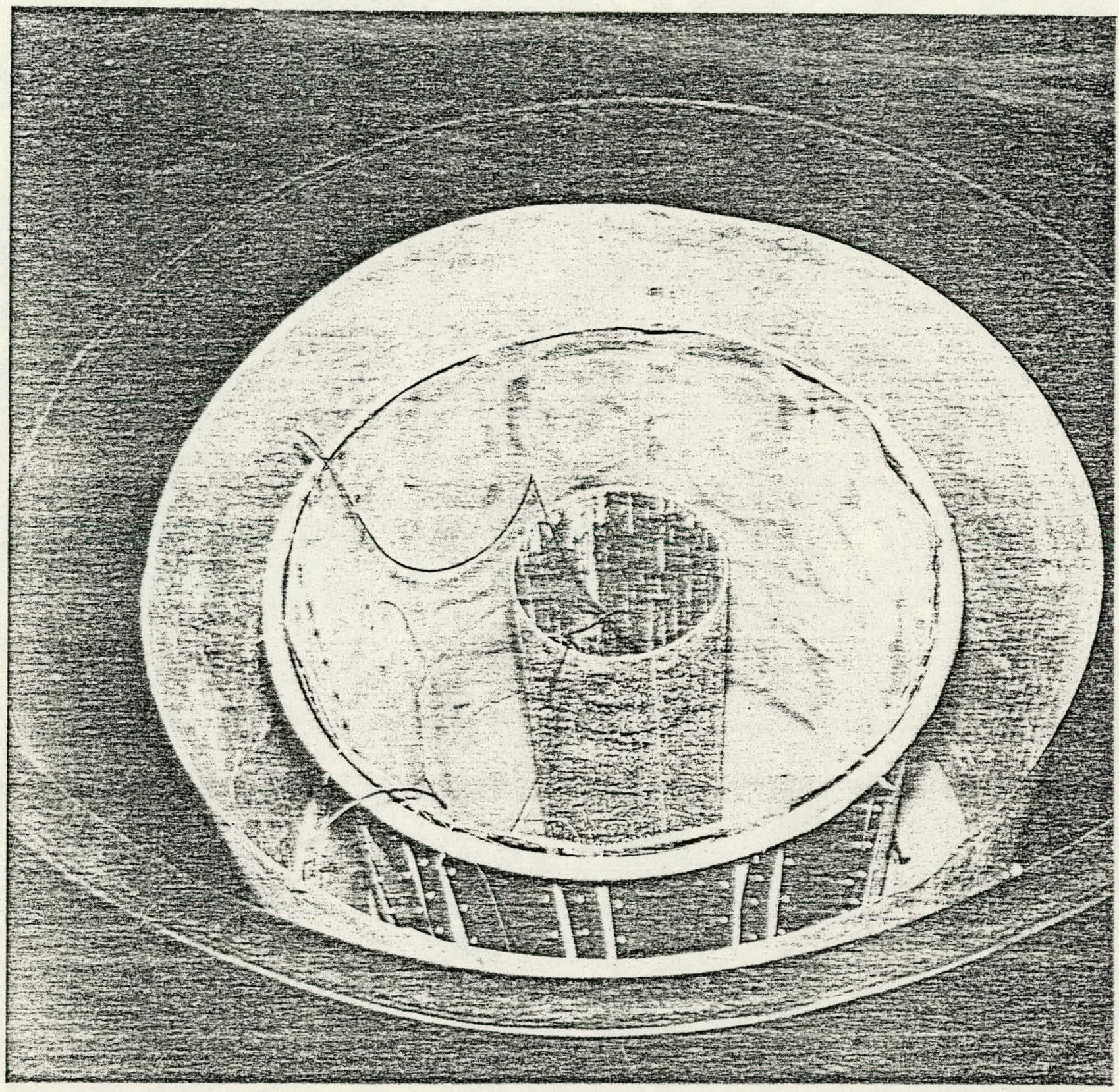

Figure 8 Electrolytic test tank 


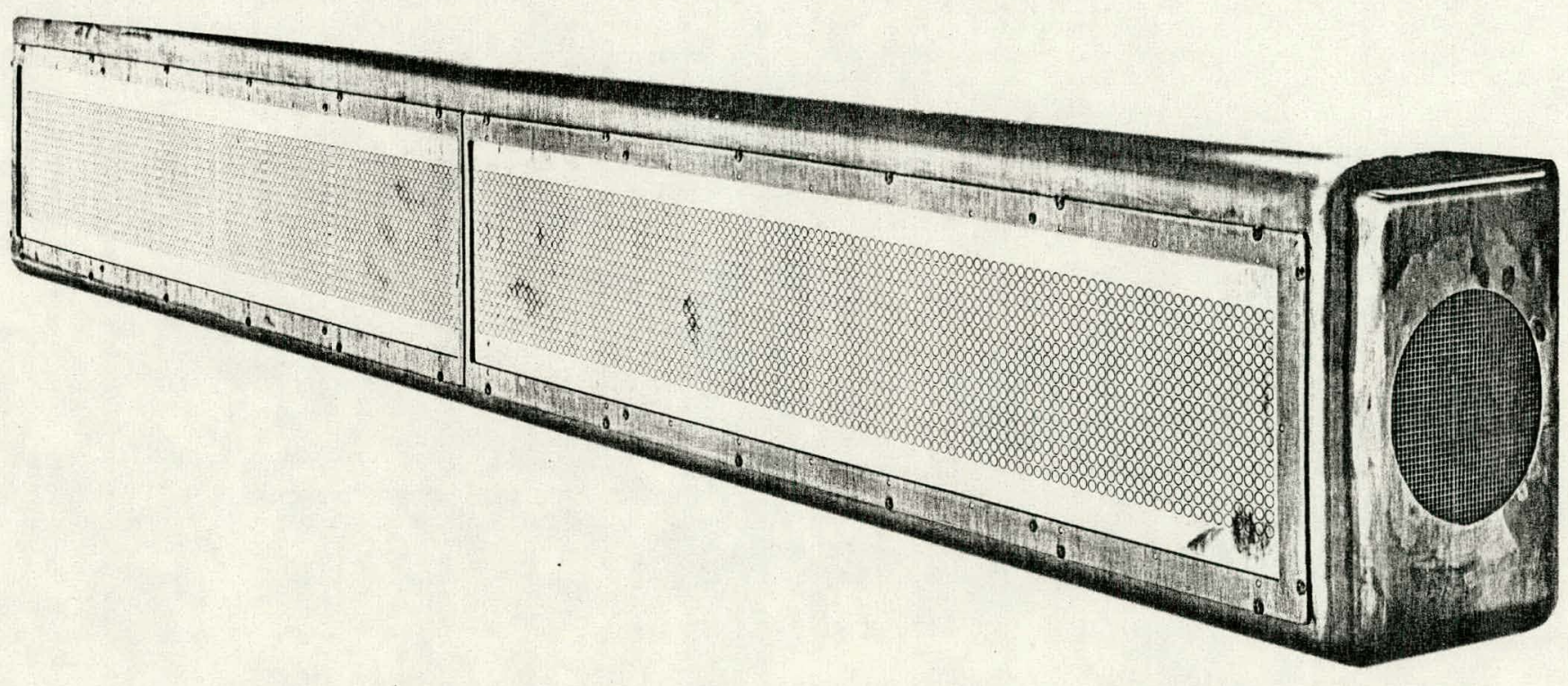





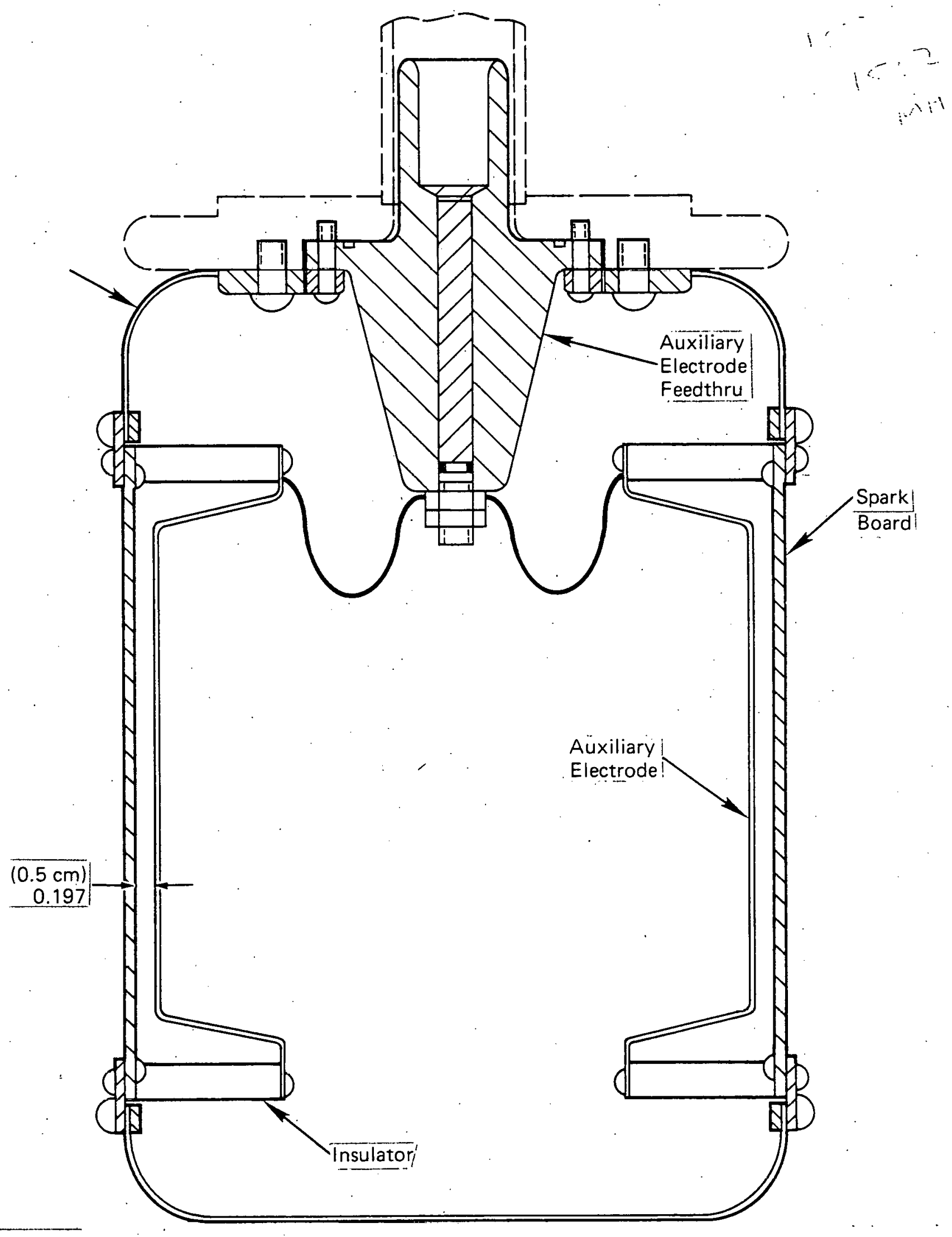

